\section{Estudio de las linternas y el extradós de las cúpulas de la Maqsura de la Catedral de Córdoba, antigua mezquita Aljama}

Pedro Marfil Ruiz

Arqueólogo

\section{Resumen}

Estudio arqueológico de las cúpulas de la Maqsura de la Mezquita de Córdoba; la limpieza de sus paramentos permitió recuperar importante información referente a la configuración original de este espacio, modificada en los siglos posteriores a su construcción.

Palabras clave: Mezquita de Córdoba, Análisis arqueológico, Maqsura, Cúpulas.

\section{Abstract \\ Archaeological study of the domes of the Maqsura at the Cordoba Mosque. The cleanness of the paramentos, tile mosaic coverings, permitted important information to be recovered regarding the original layout of the mosque, which was then modified over the centuries.}

Key words: Cordova Mosque, Archaeological analysis, Maqsura, Domes.
A lo largo de los meses de Junio, Julio y Agosto de 1998 y de Octubre de 1999, se llevaron a cabo trabajos de estudio arqueológico de la zona externa de las cúpulas de la maqsura, tanto en el extradós de las mismas como en sus linternas y cubiertas. Fueron financiados en su primera fase por la Delegación Provincial de Cultura de la Junta de Andalucía $y$, en su segunda fase, por el Cabildo Catedralicio.

La limpieza de paramentos ha permitido recuperar información referente a la estructura original de las linternas que acogen a las tres cúpulas de la Maqsura. Ejemplares que ilustran el momento cumbre del arte hispanomusulmán, no superado por las construcciones posteriores ni por la arquitectura emiral o califal anterior.

\section{LA INFORMACIÓN HISTÓRICA}

Conocemos valiosos datos acerca de la construcción de estas cúpulas y su cronología gracias a los textos de al-Idrisi. Éste relata que en el año 965, por iniciativa del califa al Hakam II, se concluyó la cúpula del mihrab y su decoración.

Los textos islámicos aportan datos precisos acerca de la fecha de construcción de estas cúpulas, cuya obra se encuentra íntimamente unida a la construcción del mihrab y la maqsura y al programa decorativo que recubre toda la zona. Hemos de referir que toda la ampliación de al Hakam II se realiza tan sólo en cuatro años, del 962 al 965 (o inicios del 966).

La cúpula central se terminó en junio del 965, a partir de cuya fecha se inician los trabajos de decoración con mosaicos de la misma. El califa Al Hakam II había «ordenado" al emperador bizantino Nicéforo Focas (963-969) que le enviase un musivario que dirigiese los trabajos. El emperador bizantino envió a este artista así como abundante materia prima para su realización.

El historiador árabe Ibn Idari nos relata lo siguiente al respecto:

En Junio del 965 se concluyó la cúpula del mihrab, trabajo que formaba parte de la ampliación de la mezquita. Se comenzó a hacer las incrustaciones de mosaico de este edificio. Al Hakam había escrito al rey de los rum (romanos) a este respecto y le había ordenado que le enviara un trabajador capaz, a imitación de lo que había hecho al-Walid ibn Abd al-Malik cuando se proyectó la construcción de la mezquita de Damasco. Los enviados del califa le trajeron al artesano de mosaicos y también 320 quintales de cubos de mosaico que el rey de los rum le enviaba a título de regalo. El Califa dio albergue y trató con generosidad al musivario, junto al cual puso a muchos de sus esclavos, trabajando con él, que adquirieron una capacidad de inventiva que les llevó a sobrepasar a su maestro. Luego trabajaron solos cuando el 


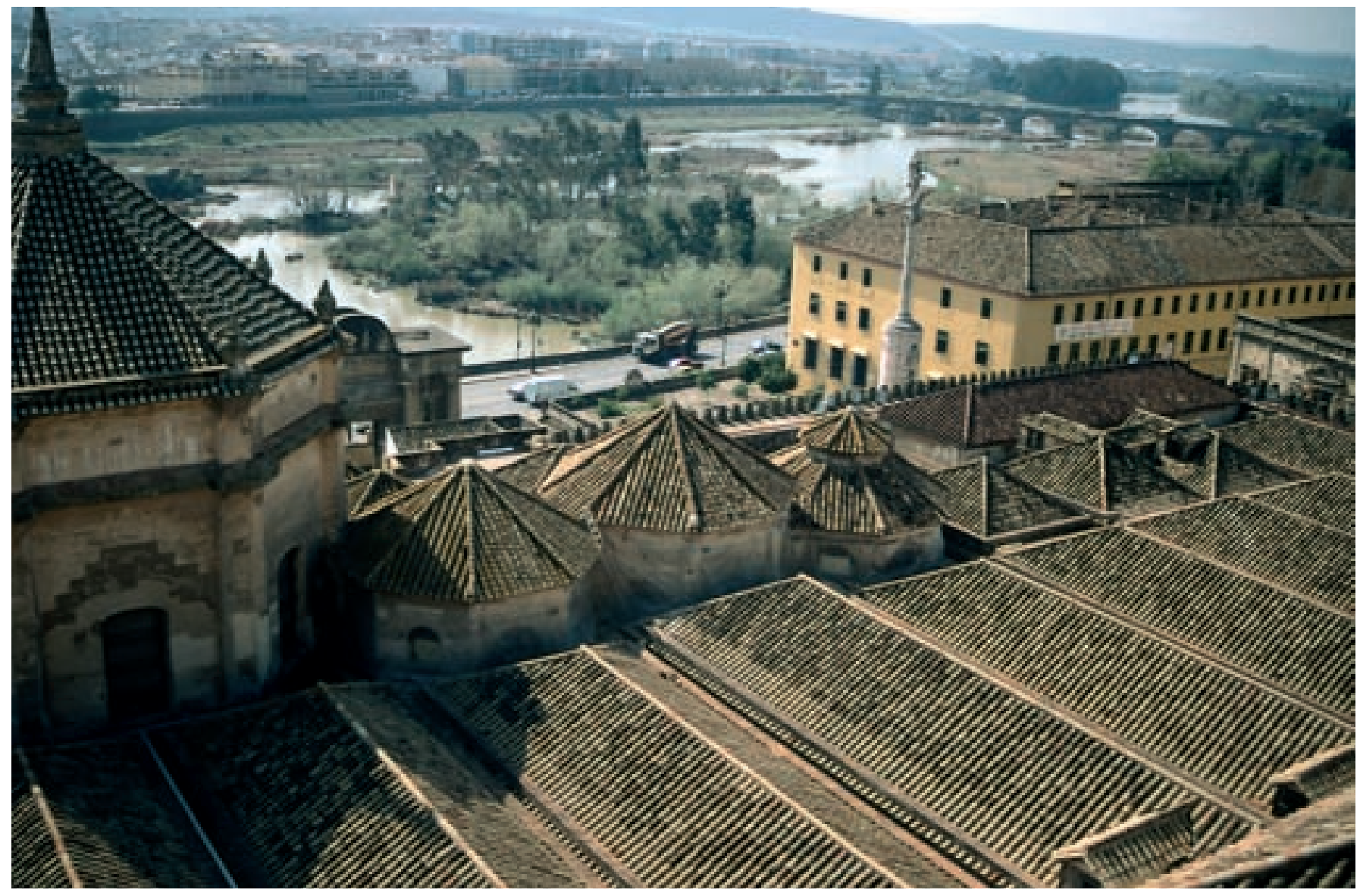

Vista general de las linternas de la Maqsura desde el sudeste

maestro musivario, de quien se podía prescindir en adelante, abandonó el país, no sin haber recibido del príncipe ricos regalos y vestimentas.

En nuestra opinión creemos que la influencia bizantina es patente en estas cúpulas, y no sólo en la ejecución de mosaicos parietales, sino también en detalles decorativos e incluso en la misma intencionalidad de crear espacios cubiertos con cúpulas.

\section{ESPACIALIDAD DE LAS CÚPULAS DE LA MAQSURA AL INTERIOR DE LA SALA DE ORACIÓN}

A nivel espacial, en el interior de la mezquita cordobesa se relacionan íntimamente las tres cúpulas de la maqsura y la cúpula de Villaviciosa, ya que sirven de realce de una planta en Tau que unifica maqsura y nave central y cuyo eje o punto axial es el mihrab.

Este espacio previo al mihrab se ve enmarcado por arquerías lobuladas tanto en su frente como en las divisiones colaterales, en las cuales se da, además de un original diseño constructivo, una profusa decoración en la que se combina la escultura decorativa y la pintura mural.
Como arranque de las linternas se sitúa en los tres espacios una cornisa decorada sobre la que se apoyan los elementos que sirven de transición visual al octógono. A pesar de que da apariencia de tratarse de cúpulas apoyadas en arcos que descargan en sus ángulos sobre trompas, es sólo un efecto decorativo. Las supuestas trompas de los ángulos, con bóvedas gallonadas y delimitadas al interior por arcos lobulados colocados en chaflán, son simplemente una solución decorativa que salva los espacios angulares dándoles apariencia estructural. Como detalle significativo y no tenido en cuenta por la historia de la investigación del monumento, hemos de hacer constar que, de tratarse de trompas, no sería lógica la existencia de ventanas sobre ellas. Por otra parte, la excavación de su cubierta ha demostrado la solidez de nuestros argumentos.

Como hemos expresado, al pasar del cuadrado al octógono en el diseño arquitectónico de la planta de las cúpulas se achaflanan los ángulos, resultando de ello la creación de ocho apoyos para la entrega de los ocho arcos entrecruzados sobre los que se dispone un octógono perfecto del que parte una bóveda gallonada, de ocho gallones separados entre sí por dobles husos de sección angular. En su cen- 
tro se traza un círculo cuyo motivo central es una estrella de 10 puntas.

La cúpula de la Bab al-Sabat, cúpula que precede el acceso al pasadizo existente en la doble Qibla, también presenta la transición del cuadrado al octógono achaflanando los ángulos, apareciendo apoyos a cada lado de los arquillos que realizan el chaflán y que cobijan a las cupulitas gallonadas decorativas. Desde estos apoyos parten cuatro parejas de arcos paralelos entre sí, desde cada lado al frontal, creando así un entrecruzamiento que da lugar a la formación de una planta estrellada de ocho puntas con espacio octogonal central. Este espacio central se cubre con una pequeña cúpula esquifada con ocho nervios decorativos de sección angular que se trazan en los ángulos del octógono. La decoración de esta cúpula reviste especial interés por conservar bajo la cal restos de decoración pictórica original.

Con respecto a la cúpula que precede a la Bayt alMal, sala del tesoro de la Mezquita, sus características son muy similares a la precedente, aunque su estado de conservación es mucho peor.

Las cúpulas sirven de marco y realce del máximo lugar sagrado de la mezquita de al-Hakam II, el mihrab o nicho de oración, punto focal que acerca esta mezquita a una concepción espacial más propia de un recinto cristiano que al de una mezquita musulmana, ya que la axialidad y la focalización del espacio hacia un punto muy concreto y muy claramente resaltado distorsiona la abstracción característica del espacio de la mezquita emiral precedente.

El espacio de la maqsura unido a la suntuosidad y diseño de la qibla y el nicho del mihrab, así como de las puertas de acceso a las cámaras que lo flanquean, hacen del conjunto algo único en la arquitectura islámica occidental.

Su conservación hasta nuestros días se debe, por una parte, al importante valor artístico que contienen tanto en su trazado como en su decoración; y, por otra, a que el Cabildo de la Catedral ha sabido apreciar a lo largo de los siglos el valor del legado histórico y se ha esforzado en mantenerlo y recuperarlo.

\section{LA INVESTIGACIÓN ARQUEOLÓGICA EN EL EXTRADÓS DE LAS CÚPULAS Y EN SUS LINTERNAS}

\section{Generalidades}

La limpieza de paramentos ha permitido recuperar información referente a la estructura original de las linternas que acogen a las tres cúpulas de la Maqsura. Estas linternas se organizan como tres octógonos con desarrollo prismático, siendo el central de mayor anchura. Están elaboradas con fábrica de sillería y presentan cubiertas a 8 aguas. Estos prismas de planta octogonal se encuentran unidos entre sí por uno de sus lados y en todas sus caras se abren huecos a modo de ventanas. Los ángulos de las linternas presentan contrafuertes poligonales que se disponen de forma decreciente en su desarrollo volumétrico vertical, presentando por ello una mayor fortaleza en la base.

Destaca la presencia de una composición decorativa en la que se relaciona directamente el interior de las cúpulas con su exterior. La linterna central conserva huecos que forman parte de los arcos de herradura de la decoración interior y que se cubren con celosías de mármol. Esos huecos son recercados por alfices triangulares. Se conservan restos

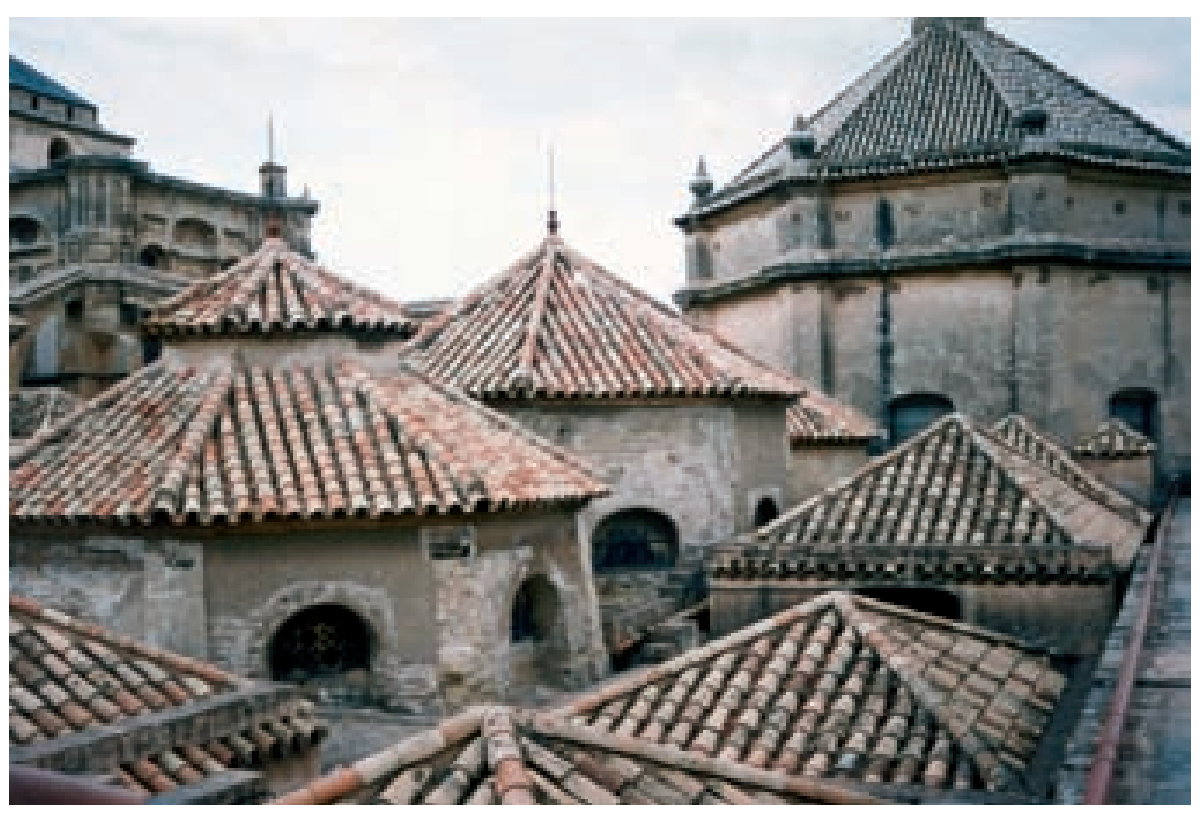


de enlucido y revestimientos pintados originales. Las linternas laterales conservan huecos que forman parte de los arcos lobulados de la decoración interior y que también se cubren con celosías de mármol. Los alfices son en este caso rectangulares. También conservan restos de enlucidos y pinturas originales.

Se han detectado dos importantes reformas de estas cúpulas, una perteneciente al año 1798 , realizada por el arquitecto francés Baltasar Drevetón y que afecta principalmente a la linterna lateral Este. La segunda actuación documentada pertenece a los trabajos del arquitecto Ricardo Velázquez Bosco, el cual cambia las cubiertas en el siglo XIX.

Los trabajos arqueológicos realizados han consistido en la limpieza de añadidos de Edad Moderna y Contemporánea que no tuviesen función estructural. Es decir, se ha respetado todo aquello que estuviese ejerciendo una acción de sostenimiento de la estructura o de protección de la misma, como es el caso de las cubiertas y de zonas con una intervención restauradora muy fuerte. Tras la limpieza de paramentos se ha realizado el levantamiento planimétrico de todos los alzados de las linternas y su estudio de estratigrafía muraria. Además se ha realizado la excavación de los rincones existentes en los encuentros de los lados de los octógonos. La excava- ción de estas zonas de cubierta se hacía necesaria para eliminar la humedad provocada por los rellenos de tierra existentes bajo las cubiertas de teja. En el presente artículo presentamos las conclusiones generales que pueden extraerse del trabajo realizado, así como los alzados coloreados de las caras externas de las linternas. La numeración designa con números correlativos todas las caras externas de las tres cúpulas, siguiendo el sentido de las agujas del reloj, siendo designado como lado 1 el lateral nordeste de la cúpula oriental.

\section{La cúpula central}

La linterna octogonal de la cúpula central presenta unas dimensiones mayores que las laterales, y su diseño y decoración arquitectónica es también distinta a lo presentado por las que la flanquean.

Esta linterna de la cúpula central presenta huecos que pertenecen a la zona superior de los arcos de herradura interiores, que se ven enmarcados por un alfiz poco común. Se trata de alfices rematados en mitra o en ángulo. Su uso no se da en otros edificios hispanomusulmanes, aunque sí se emplea dentro del programa decorativo de la zona del oratorio ampliada por al-Hakam II. Se documenta la presencia de este tipo de alfiz en la decoración interior de la

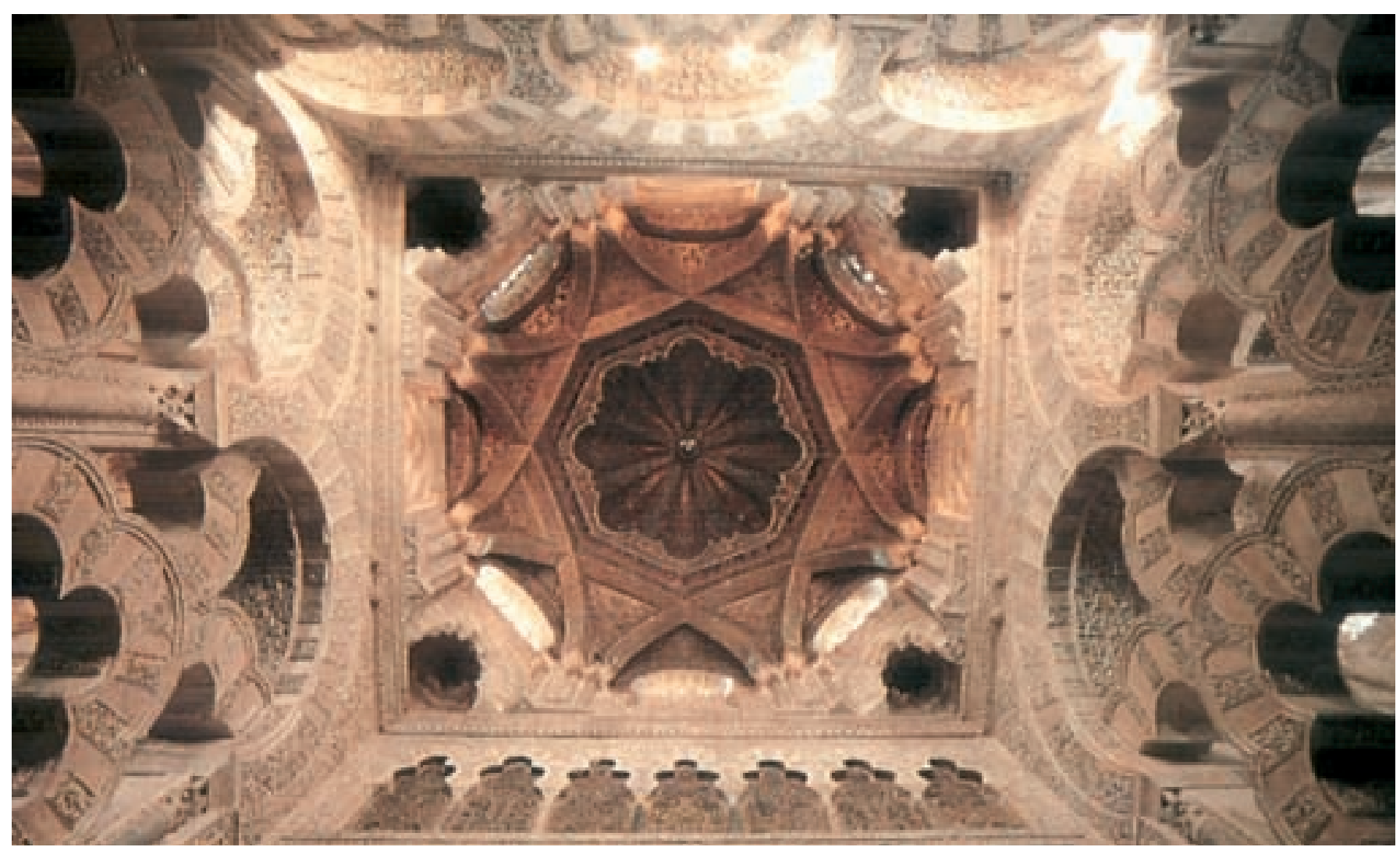

Interior de la cúpula central de la Maqsura 
cúpula central de la maqsura y en la decoración interna de una puerta de la fachada oeste de al-Hakam II.

En origen dichos huecos no estaban cerrados, pero en un momento islámico posterior a la construcción se dispusieron en ellos, como protección frente a las inclemencias meteorológicas y a la vez como adorno que tamiza la luz, celosías marmóreas y de piedra arenisca. La colocación de las celosías se realiza mediante un encachado de ladrillos, quedando tapados en algunos casos los estucos pintados a la almagra de la decoración de estas ventanas.

Las caras documentadas de esta cúpula central son las que reciben los números $5,6,7$ en la zona norte, $y$ $15,16,17$, en la zona sur. Al presentar dos lados unidos a las dos linternas laterales sus alzados externos se reducen a seis.

En las láminas 1 y 2 puede observarse el alzado del lado 5. La lámina 1 representa el alzado coloreado de este lateral de la linterna central, tratándose de una estructura perteneciente en su totalidad a la época Califal. También puede observarse la relación, a nivel de cotas, de la linterna y la canalización que recorre esta zona de este a oeste. Se trata de un colector principal de la cubierta, que recoge aguas de las canalizaciones longitudinales a las naves y las desvía hacia las fachadas laterales. Esta canalización permite el desarrollo de las cúpulas de la maqsura sin interferencia importante del paso de los desagües de las cubiertas.

En este alzado pueden observarse las características que presentan en general todas las caras de esta linterna prismática central. A izquierda y derecha encontramos este paño enmarcado por dos pilares cuya fábrica de sillería se encuentra perfectamente trabada con la de los muros. Estos pilares albergan en su interior el cruce de vigas de madera que constituyen el atado o encadenado de la cúpula.

El desarrollo del muro se ve alterado por la apertura de una ventana, por lo que su diseño arquitectónico acusa una ejecución distinta en la zona de la ventana que en su desarrollo vertical sobre esta. Así pues, vemos cómo se consigue un arco de descarga a través de la colocación de gruesas dovelas en la zona de clave del arco, mientras que en el desarrollo del mismo se produce la talla de los mismos sillares de la base del muro para conseguir el juego de profundidades o rasantes.

Sillares aparejados a tabla producen la transición hasta una hilada de sogas, que buscan con esa disposición proporcionar un espacio más amplio en la zona interior de la cubierta, para colocar tres hiladas a tabla de módulo pequeño en la zona más alta.

Lo más interesante de estos muros de la linterna central es la estructura de la ventana que, como ya hemos comentado, aparece como el hueco formado por la zona más

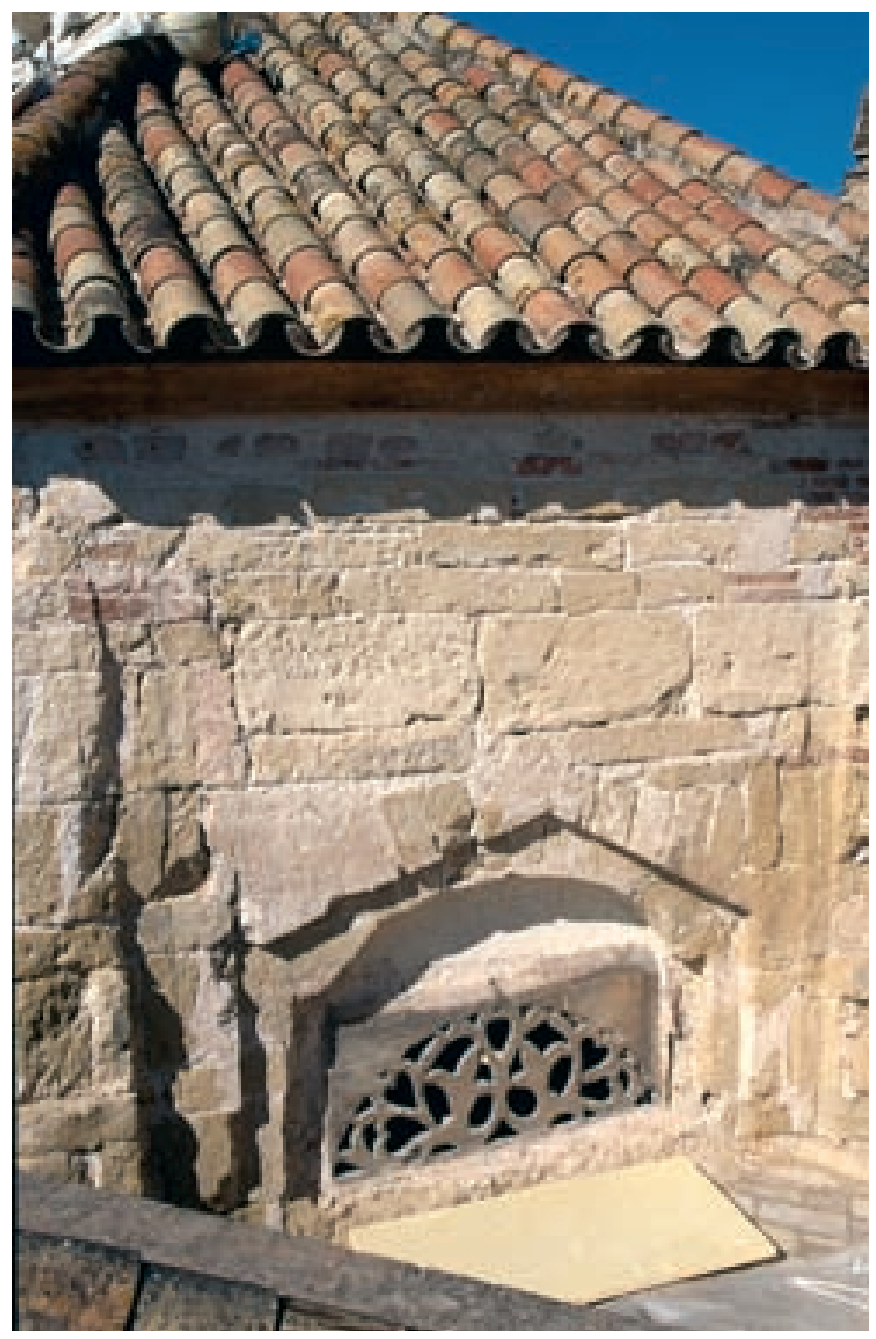

Linterna de la cúpula central, lado 17

alta del arco de herradura del interior de la cúpula y se enmarca por un alfiz cuya zona superior se diseña de forma angular apuntada hacia arriba. El alfiz se resalta por medio del retalle de la fábrica del muro.

Al rebajar la cubierta de Edad Moderna hasta las cotas medievales pudo recuperarse parte de la decoración mural que recubría esta linterna. Se trata de pintura geométrica de diseño muy simple, de color rojo a la almagra sobre enlucido de cal y arena, formando fajas decorativas que sirven de realce del diseño arquitectónico.

En este lateral 5 se da la presencia de una fase islámica posterior a la construcción original y que consiste en la colocación de la celosía, sustituyendo a la fábrica que cubría el hueco de la ventana.

El aspecto original de los huecos de las ventanas solamente se ha conservado en el lado 6 (láminas 3, 4 y 5). En este muro la ventana esta cubierta por fábrica en la que se abren cuatro óculos. No sólo tiene importancia la existencia de esta solución constructiva en el ámbito externo de las 


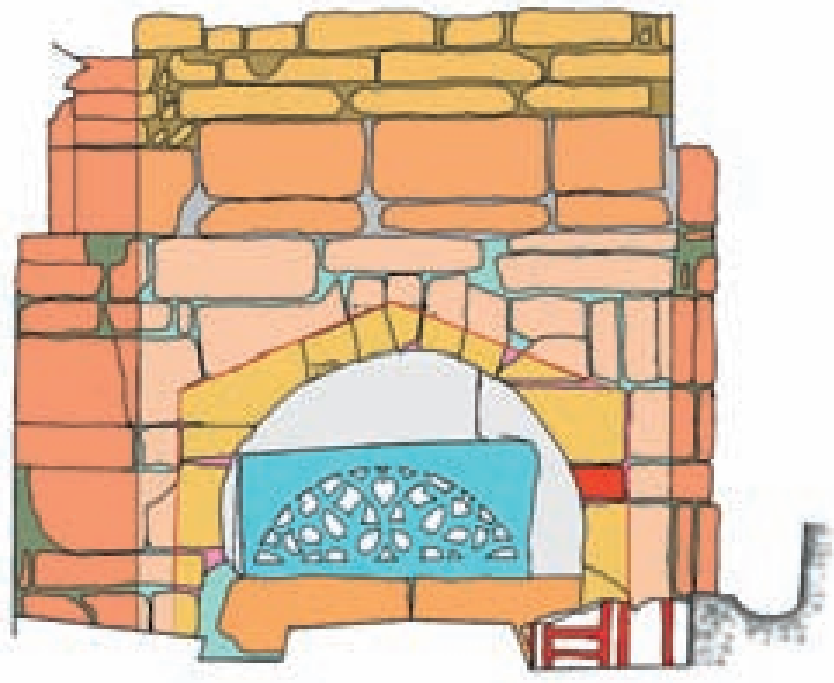

Lámina 1. Cúpula central, lado 5

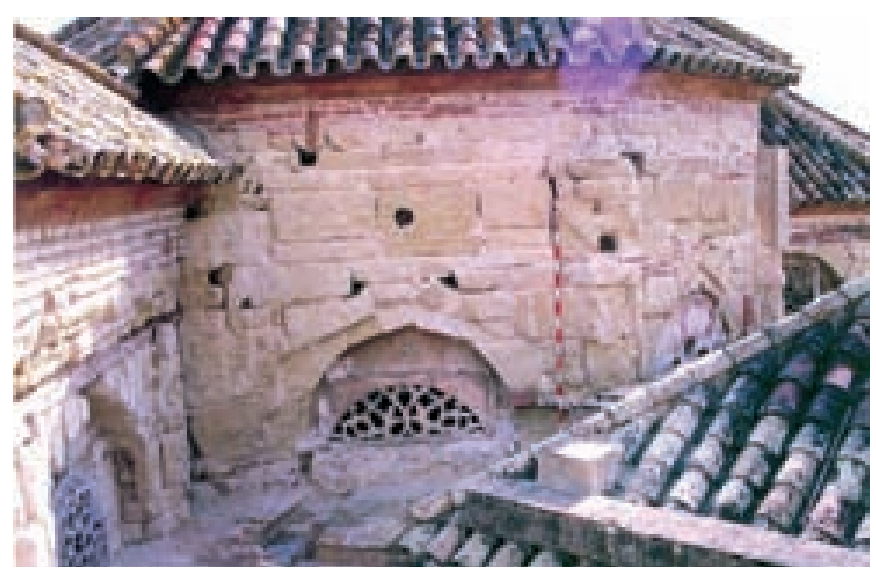

Lámina 2. Cúpula central, lado 5 (fotografía del alzado)

linternas, sino que al interior repercute en la presencia de decoración que recubre toda su superficie interna, apareciendo los óculos como huecos estrellados al interior.

En la lámina 3 se representa el alzado de la cara 6 de esta linterna central, que presenta en general unas características muy parecidas a lo comentado para la cara 5. En este caso se ha representado en la zona superior la fábrica recrecida por Velásquez Bosco, así como el pilar de la derecha del dibujo, que es fruto de la restauración realizada por Baltasar Drevetón a fines del siglo XVIII.

Es destacable de esta cara la conservación de la estructura del alfiz y del arco de herradura que cubre el hueco de la ventana. Se están utilizando tres rasantes para destacar los distintos elementos de la composición, la del arco de herradura, la del alfiz y la del muro.

En la lámina 5 se muestra una fotografía de la zona interna de este lado de la cúpula. Hemos de destacar la pre-

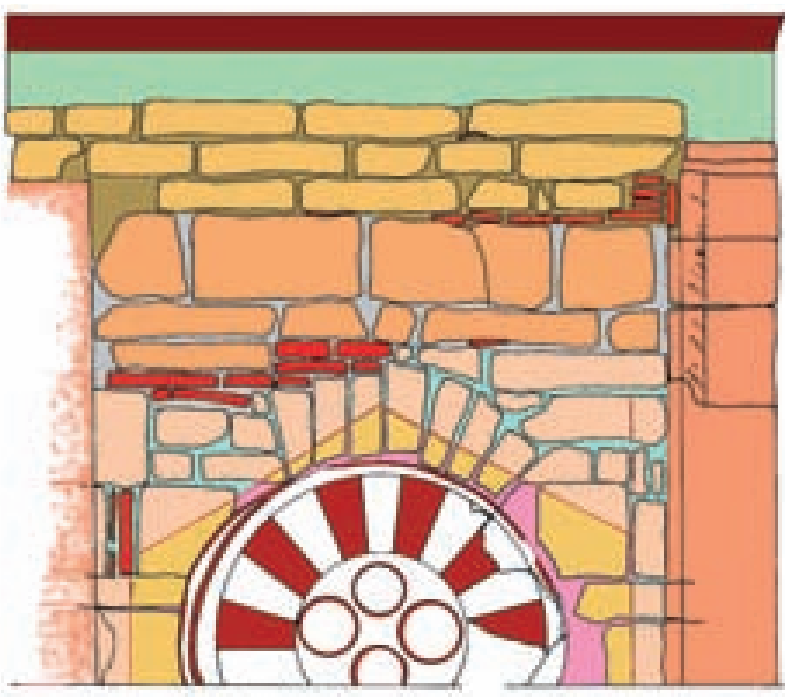

Lámina 3. Cúpula central, lado 6

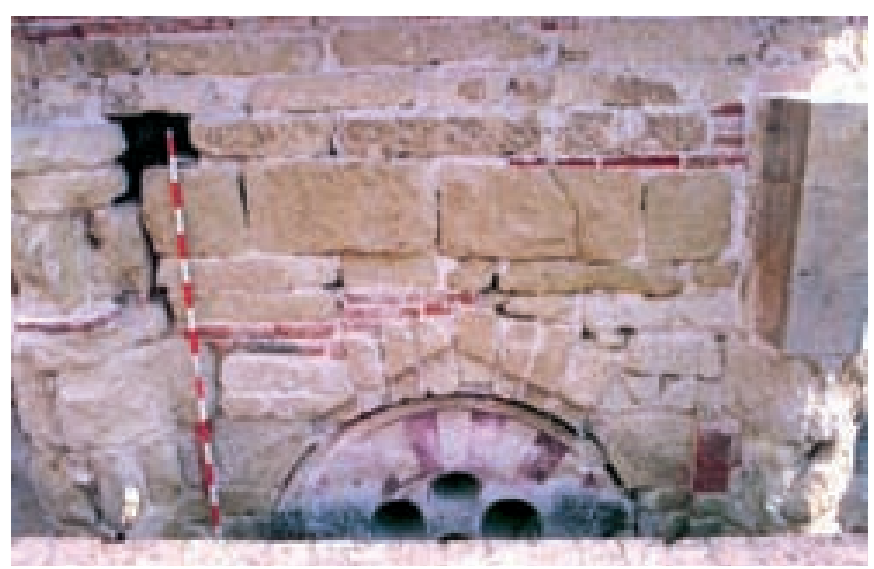

Lámina 4. Cúpula central, lado 6 (fotografía del alzado)

sencia de decoración en la que se emplea el diseño del alfiz triangular como trasunto de lo que hemos observado al exterior.

El lado 7 (lámina 6) presenta unas características muy similares a las ya comentadas, destacando lo elaborado del diseño de la celosía, que en este caso esta diseñada ex profeso para su colocación en esa disposición.

Las linternas se adaptan perfectamente a las cotas de las cubiertas que se les entregan y a las canalizaciones circundantes. Esto puede observarse bastante bien en el caso del lado 15 de la linterna central (lámina 7). En su representación planimétrica puede observarse la posición de las dos aguas de la cubierta que parte desde él. En este paño destaca la solución adoptada para la descarga del arco para la ubicación de la ventana, dándose la presencia de una hilada de tizones que continúan de forma orgánica el arco adintelado del hueco de ventana. 


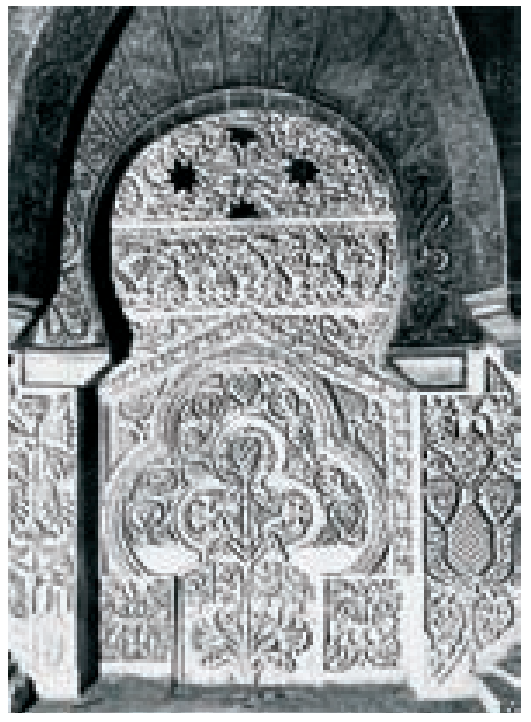

Lámina 5. Cúpula central, interior de la cúpula en el lado 6

Con respecto a la celosía destaca la presencia de un retacado de ladrillo que le sirve de asiento. Se trata de ladrillos con características formales muy similares a los empleados en las dovelas de ladrillo de los arcos del interior de la sala de oración.

El lado 16 de la linterna de la cúpula central es uno de los mejor conservados, destacando la celosía empleada en el cubrimiento del hueco de la ventana. Creemos que es una pieza diseñada para esa ubicación, y se encuentra encajada por medio del retalle de las piezas de la fábrica de sillería y con el emparchado de fábrica de ladrillo que se aplica en el tímpano del arco. En este caso la descarga del arco está mucho mejor lograda en su ejecución, empleán-

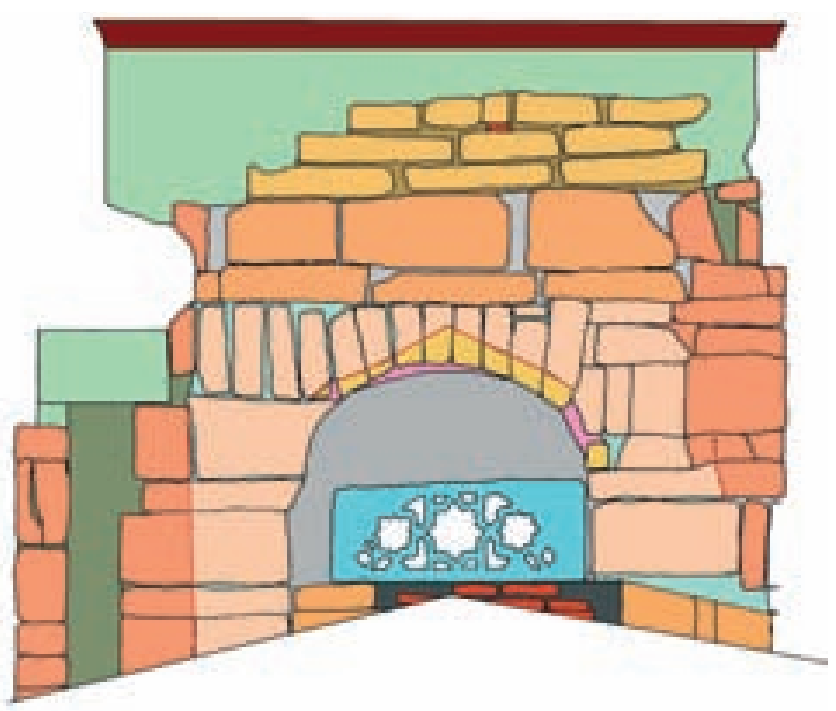

Lámina 7. Cúpula central, lado 15

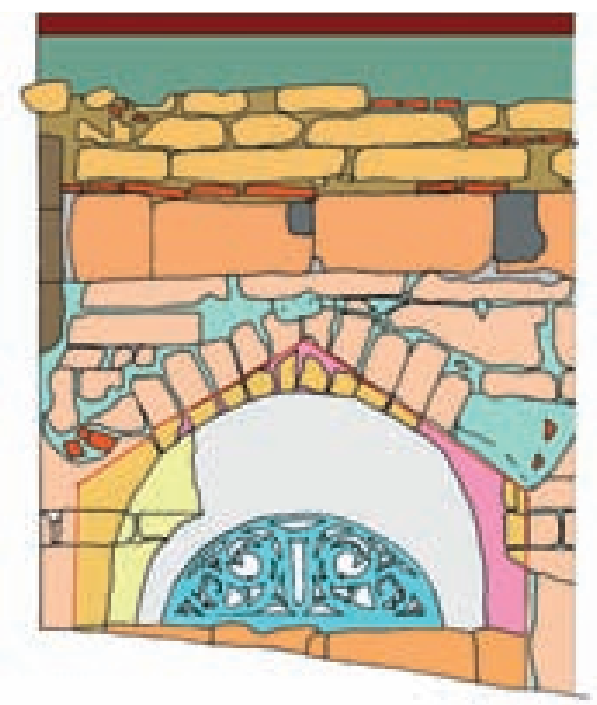

Lámina 6. Cúpula central, lado 7

dose sillares de módulo menor y aparejándose de forma más correcta.

El lado 17 (lámina 9) de la linterna central presenta unas características muy similares a lo observado en las anteriormente comentadas.

Hemos de destacar la originalidad del diseño de esta linterna, en la que se entremezclan de forma armónica la imagen volumétrica, el diseño arquitectónico de sus muros, la funcionalidad de la estructura como elemento protector de la cúpula y sostén de sus elementos internos, y su decoración interna y externa. Se trata sin duda de una de las obras cumbres de la historia del arte hispanomusulmán.

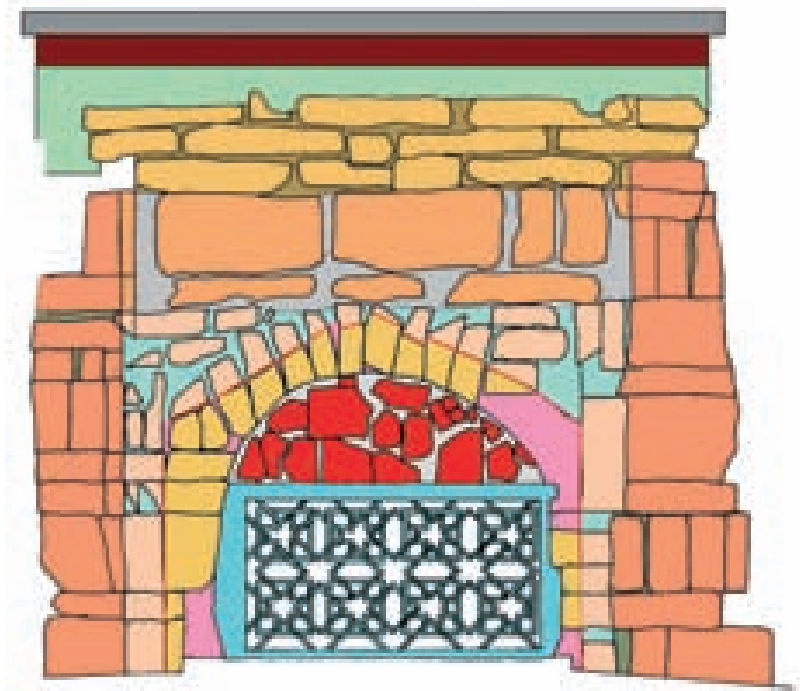

Lámina 8. Cúpula central, lado 16 


\section{La linterna de la cúpula lateral este}

Las linternas laterales presentan unas dimensiones menores que la central y una menor altura. En ellas se trazan grandes arcos de herradura como ventanas, presentado en este caso un alfiz cuadrangular. Se encontraban coronadas posiblemente por una cornisa de la que quedan restos reutilizados en reformas de la cubierta de las mismas.

La cúpula lateral este o cúpula que precede a la Bayt al-Mal (Cámara del Tesoro) es la que más ha sufrido las transformaciones fruto de su restauración en el siglo XVIII.

En su lado 1 puede observarse de forma muy clara esta reforma y reconstrucción, la cual implicó al exterior la desaparición del hueco de ventana aquí existente en origen, aunque se mantiene su presencia al interior de la cúpula. Asimismo se le adosa uno de los pilares angulares de la capilla de Santa Teresa lo cual incidió en sus cubiertas.

El hueco de ventana fue cerrado mediante el retacado con fábrica de ladrillo. El acabado del muro en esta reforma del siglo XVIII adquiere un enlucido de argamasa de cal en el que se dibuja un despiece de falsa sillería avitolada. Un elemento clave para conocer la fecha y naturaleza de esta reforma es el representado por un grafito pintado sobre el enlucido, que dice lo siguiente: se compuso esta capilla el año 1798 (lámina 24).

Esta zona es una de las partes más deterioradas de todo el interior. El principal motivo de este deterioro es la entrada de abundante humedad transmitida por capilaridad a través del muro del lucernario. Posiblemente las obras de la capilla de Santa Teresa afectaron al paso de la canalización Norte-Sur allí existente.

La celosía de este muro, como dijimos anteriormente, no puede ser observada desde el exterior al haber sido tapia- da en el siglo XVIII, aunque sí puede verse desde el interior; hemos de destacar que el diseño de su lacería se adapta perfectamente a las características formales del arco lobulado. A falta de una observación directa pensamos que posiblemente se deba a una reposición y no a un elemento original. Nos basamos para decir esto en la presencia de rosetas en los espacios cuadrangulares formados por los lazos, así como en la adaptación de esta lacería a las curvas formadas por los lóbulos. Esperamos poder comprobar este supuesto en futuros trabajos desde el interior de la cúpula.

Ha recibido el n. ${ }^{\circ} 2$ el lado nordeste del lucernario de la cúpula del tesoro. Se trata de un muro que comparte casi todas las características del muro ya descrito, con la particularidad de que, en este caso, la reforma sí ha respetado el hueco de ventana allí existente en origen. La excavación del hombro de la cúpula en esta zona ha permitido rebajar el nivel de cubierta del mismo, eliminando de esa forma la entrada de humedad por este lugar.

El hueco de ventana fue transformado en el s. XVIII, retacándose la estructura original con fábrica de ladrillo y dándole forma de arco de medio punto abocinado. El revestimiento es también de argamasa de cal con tratamiento de superficie mediante despiece de falsa sillería avitolada. Al interior de la bóveda se observa asimismo la existencia de arco lobulado. La celosía se adapta al trazado de los lóbulos.

Ha recibido el número 3 (lámina 11 y 12) el lado norte del lucernario de la cúpula del tesoro. Se trata de un muro que también sufrió las reformas del siglo XVIII. Podemos observar la estructura general del muro y hueco de ventana del lucernario. Se encuentra enmarcado o flanqueado en sus lados por pilares de sillería de sección poligonal. Estos pilares se

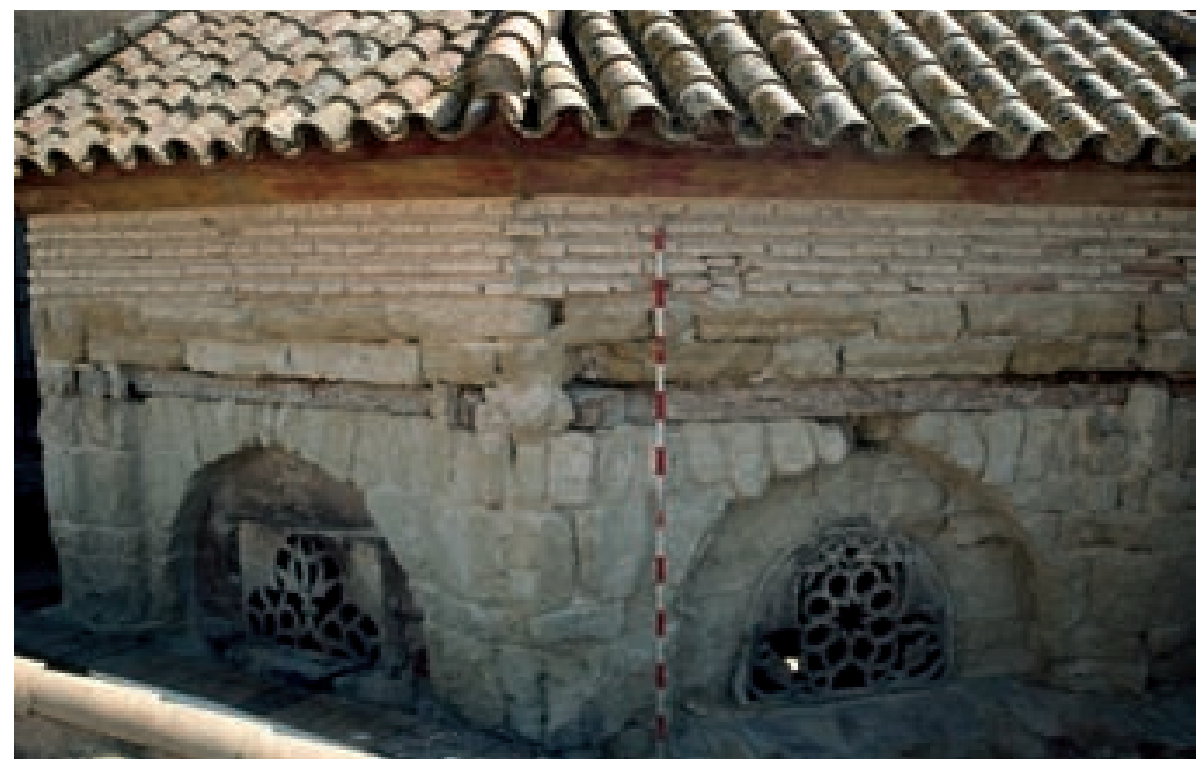

Alzado de la linterna de la bóveda lateral este 


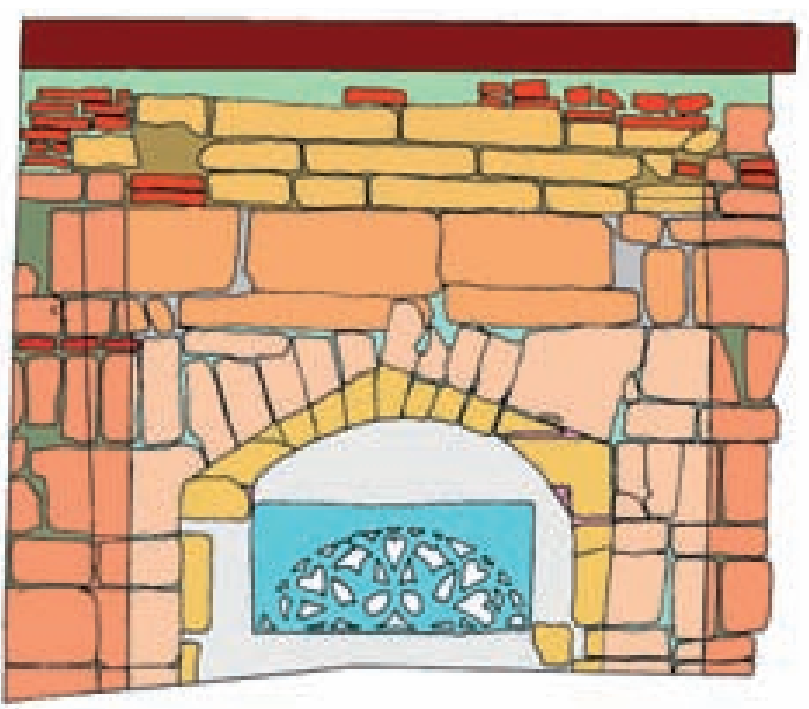

Lámina 9. Cúpula central, lado 17

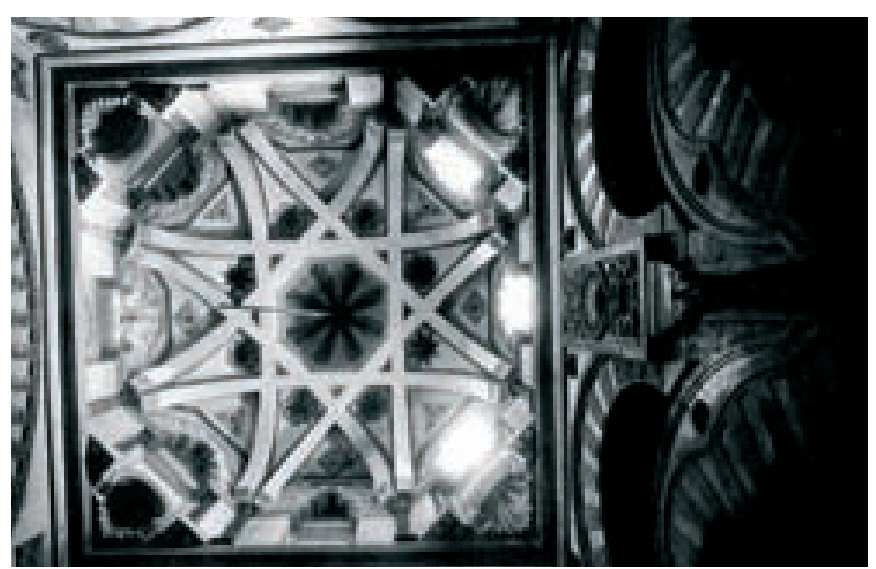

Lámina 10. Interior de la cúpula lateral este

encuentran dispuestos en los ángulos de todos los lucernarios. En la zona superior de los pilares se produce el cruce interno de las vigas que sostienen las cúpulas, atándolas de esa forma a la estructura externa mediante encadenado de madera.

En el espacio entre los pilares angulares se establecen los muros; en este caso, el muro 3, ofrece una muestra magnífica de la organización de los paramentos exteriores de los lucernarios de las cúpulas laterales. Se abre un arco de herradura que se cierra al interior de la cúpula, albergando una celosía de piedra que presenta decoración vegetal.

El aparejo del muro se traba perfectamente a los pilares, estando trabajados los sillares de forma que algunas de las piezas pertenecen al pilar y al muro.

El arco de herradura se traza por tanto en base a la conjunción de unos arranques anclados a los pilares y que han sido labrados formando arco, y por otro lado a dovelas

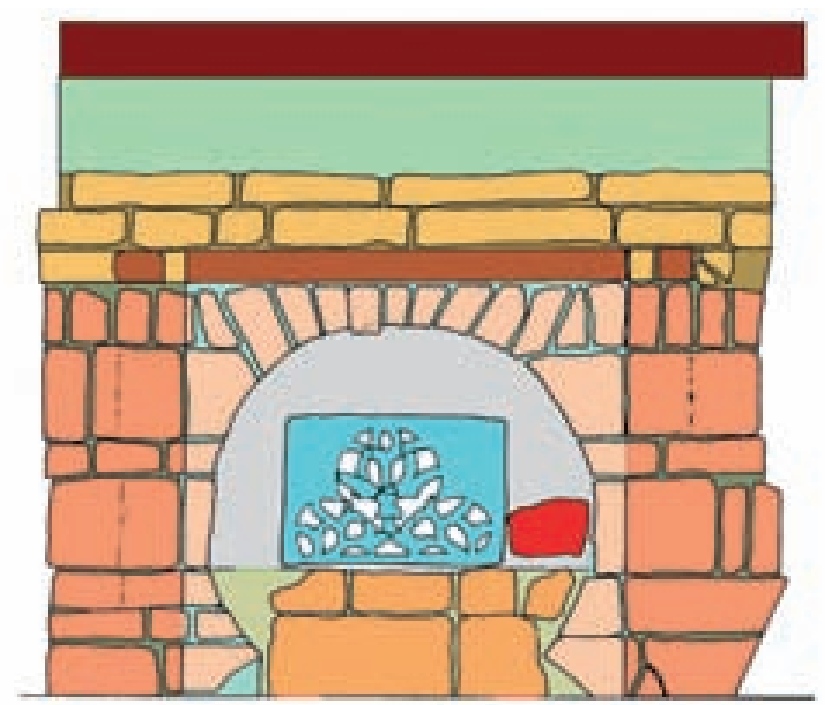

Lámina 11. Cúpula este, lado 3

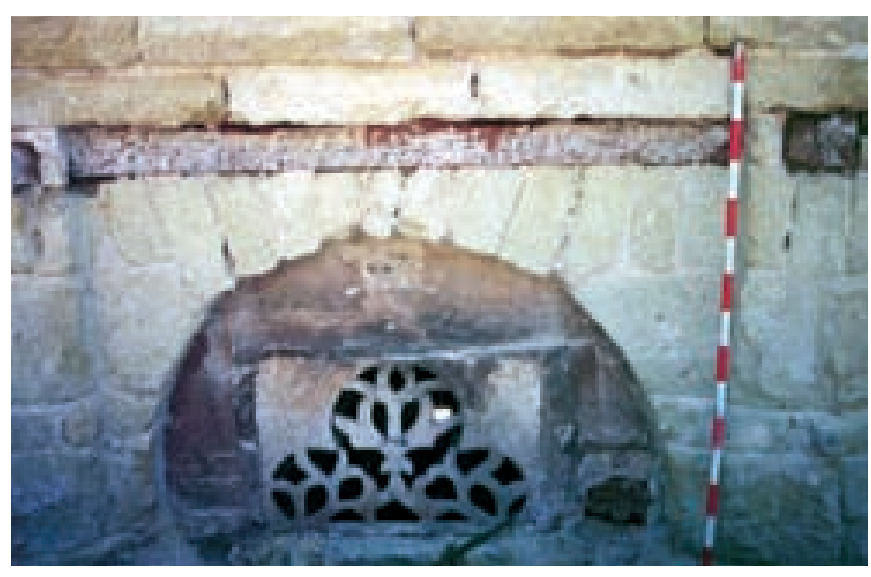

Lámina 12. Cúpula este, lado 3 (fotografía del alzado), obsérvese el encadenado de madera

que hacen función de arco adintelado sobre las que descansan las vigas de madera. Posiblemente las cabezas de las vigas al exterior fueron protegidas mediante enfoscado de argamasa, el cual lógicamente debió perderse al cabo de poco tiempo tras su colocación.

La cubierta de la cúpula acusa su reforma histórica, que dio lugar a la dislocación de las últimas hiladas, recolocándose las piezas que formaban la cornisa o alfiz del arco. La cubierta debía ser más baja que en la actualidad, por lo que se recrecen los muros en la parte superior mediante fábrica de ladrillo.

Hemos de destacar la celosía del hueco de ventana de este lateral. Esta pieza marmórea se adapta a la forma del arco lobulado interior. Presenta una decoración vegetal simétrica, con un tallo que actúa de eje central. Hojas carnosas muy simples parten a pares desde el tallo. Se trata sin duda de una pieza labrada ex profeso para su colocación en esta ubicación. 
El lado noroeste del lucernario de la cúpula del tesoro ha recibido el número 4 (lámina 13). Se trata de un muro que también sufrió las reformas del siglo XVIII. La reforma, al igual que en el muro 3, sí ha respetado el hueco de ventana allí existente en origen. Como vimos en la cara 3, en la cara 4 también ha sido alterada la zona superior de la fábrica, recolocándose las piezas que formaban el alfiz o cornisa. También se aprecia el recrecido de fábrica de ladrillo para la cubierta.

Se observa la misma técnica constructiva que referimos al hablar de la cara anterior, es decir, las dovelas realmente hacen la función de arco adintelado, formándose el arco de herradura tallando las piezas de sillería.

Este muro 4 se une al muro 5, que pertenece a la bóveda central, quedando por tanto uno de los muros de la bóveda compartido por la bóveda central y la bóveda del tesoro, que sería el muro Este de la primera y Oeste de la segunda. Dicho muro sólo puede apreciarse desde el interior.

Ha recibido el número 18 el lado sudoeste del lucernario de la cúpula del tesoro. Como característica más importante hemos de reseñar su reforma y reconstrucción en momentos del s. XVIII. Esta reforma implicó la desaparición del hueco de ventana aquí existente en origen, aunque se mantiene su presencia al interior de la cúpula.

Ha recibido el número 19 el lado sur del lucernario de la cúpula del tesoro. La reforma del siglo XVIII no implicó en esta cara la desaparición del hueco de ventana, aunque sí fue profundamente alterado, retacándose la estructura original con fábrica de ladrillo y dándole forma de arco de medio punto abocinado. El revestimiento es también de argamasa de cal con tratamiento de superficie mediante despiece de falsa sillería avitolada.
Se sitúa el muro 20 en la zona de encuentro entre la capilla de Santa Teresa y la cúpula del tesoro, quedando este espacio como un rincón muy alterado por la construcción de dicha capilla.

\section{La linterna de la cúpula lateral oeste}

Esta linterna lateral presenta unas características muy similares a la linterna que precede a la Cámara del Tesoro. Sus dimensiones también son menores que las de la linterna central, y tiene menor altura. En ella volvemos a encontrar el trazado de grandes arcos de herradura como ventanas, con alfices cuadrangulares. Posiblemente se encontraría coronada por una cornisa, al igual que hemos propuesto para la linterna de la cúpula este.

La cúpula lateral oeste, que precede a la Bab al-Sabat (Puerta del Pasadizo), ha sufrido menos transformaciones que la lateral este, aunque en general su deterioro es más acusado que el apreciado en la linterna central. Hemos de destacar que el encadenado de madera de la cúpula se aprecia muy bien desde el exterior.

Pueden documentarse 7 de sus lados, compartiendo uno con la linterna central, que sólo puede apreciarse desde el interior.

El primero por el nordeste es el lado 8 (lámina 14), del cual destaca el trazado de su arco de herradura, con dovelas bien aparejadas, aunque cortadas por la ubicación de las vigas de madera. También es destacable en este muro la presencia de pinturas murales que evidencian su función como refuerzo visual del diseño arquitectónico mediante la aplicación de fajas de color rojo a la almagra en las aristas y ángulos formados por los elementos que componían el diseño de

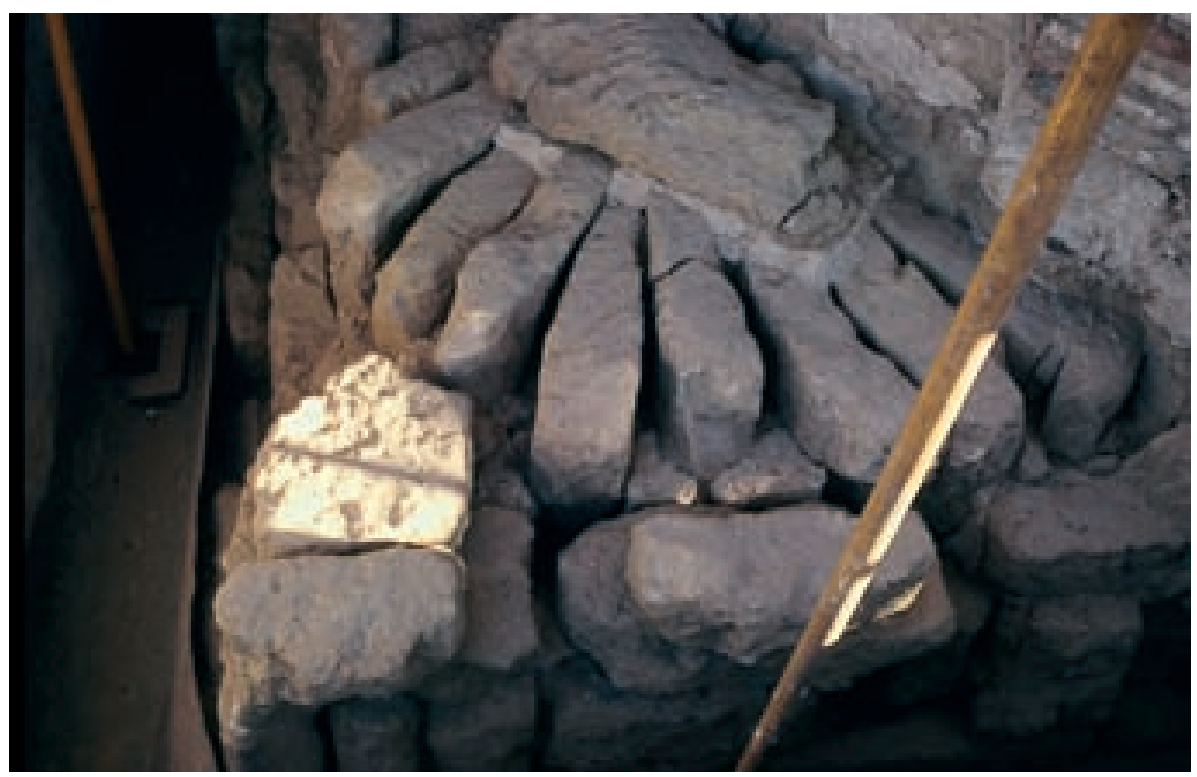

Detalle de la estructura que cubre a una de las falsas trompas de la bóveda lateral oeste 


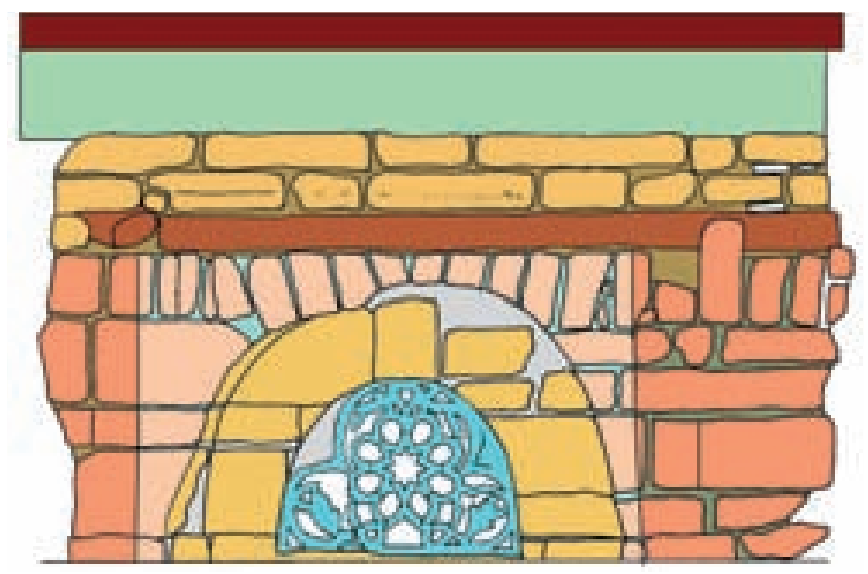

Lámina 13. Cúpula este, lado 4

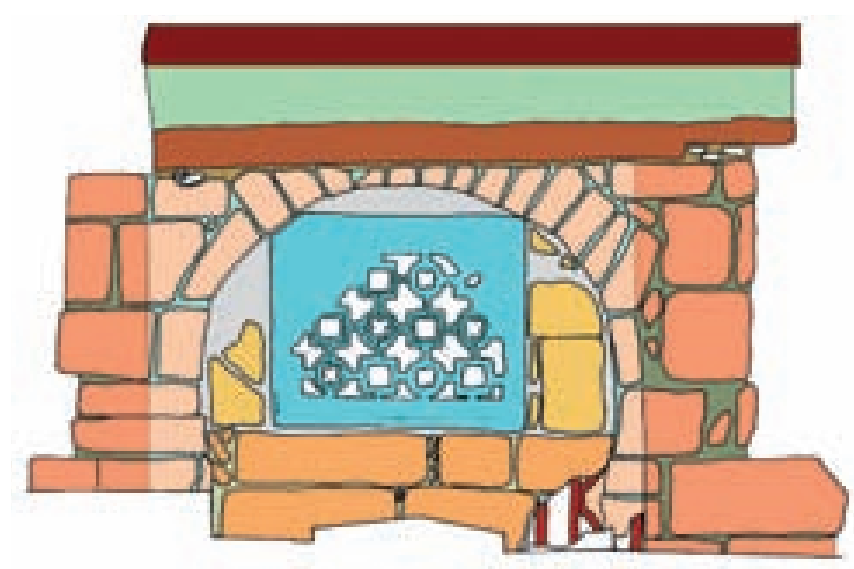

Lámina 14. Cúpula oeste, lado 8

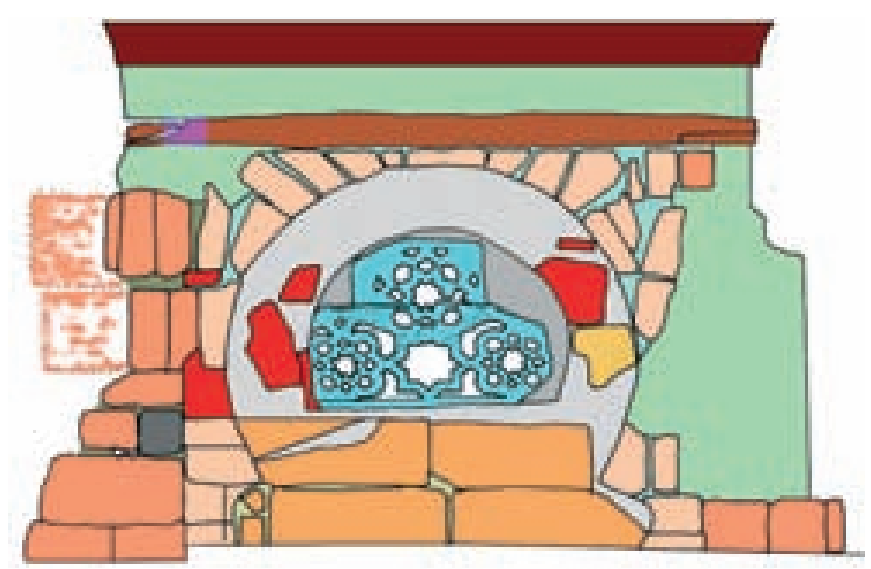

Lámina 15. Cúpula oeste, lado 9

la ventana. La celosía de esta ventana es de época gótica y obedece posiblemente a la sustitución de una pieza anterior.

El lado 9 (lámina 15) presenta unas características muy similares al lado 8 y a lo documentado en la cúpula este. Destaca de esta zona la reconstrucción moderna que se aprecia de su pilar derecho, así como la celosía, elaborada con dos piezas reutilizadas.

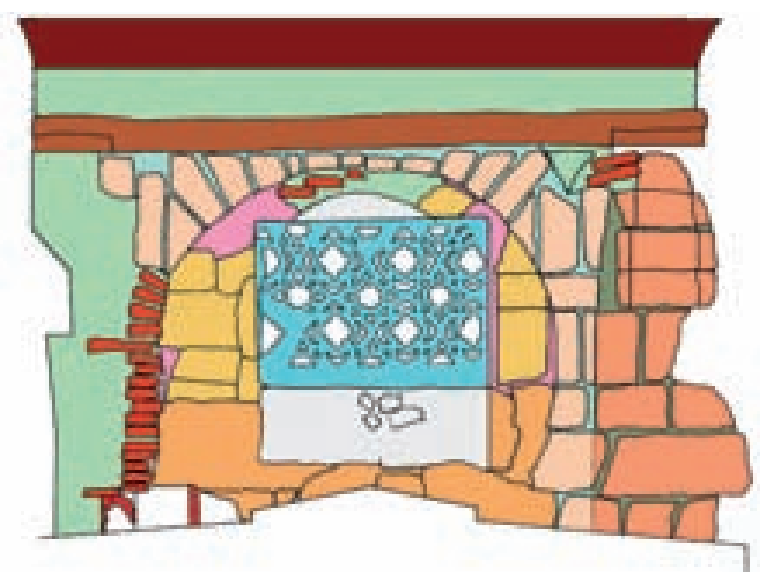

Lámina 16. Cúpula oeste, lado 10

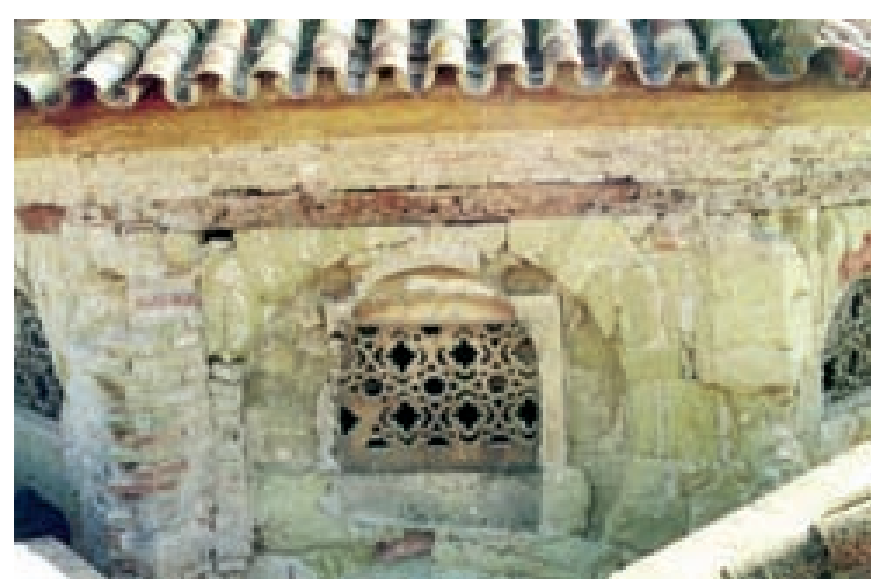

Lámina 17. Cúpula oeste, lado 10 (fotografía del alzado)

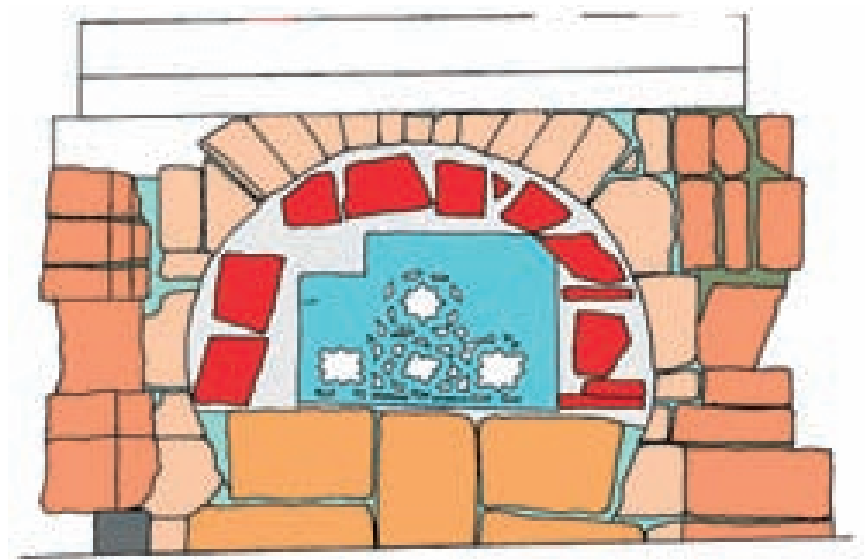

Lámina 18. Cúpula oeste, lado 11

El lado 10 (láminas 16 y 17) sigue la tónica de lo ya comentado, destacando la presencia de una celosía reutilizada.

El lado 11 (lámina 18) es el lateral oeste de esta cúpula occidental. Destaca el trazado de su arco de herradura, que presenta un aparejo muy bueno. También es interesante la presencia de dos piezas reutilizadas en su celosía, un cancel visigodo y una pieza emiral. 


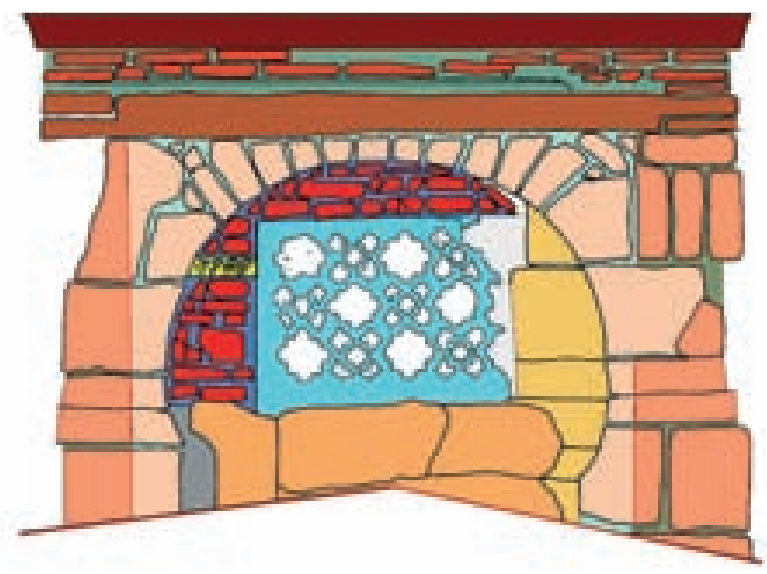

Lámina 19. Cúpula oeste, lado 12

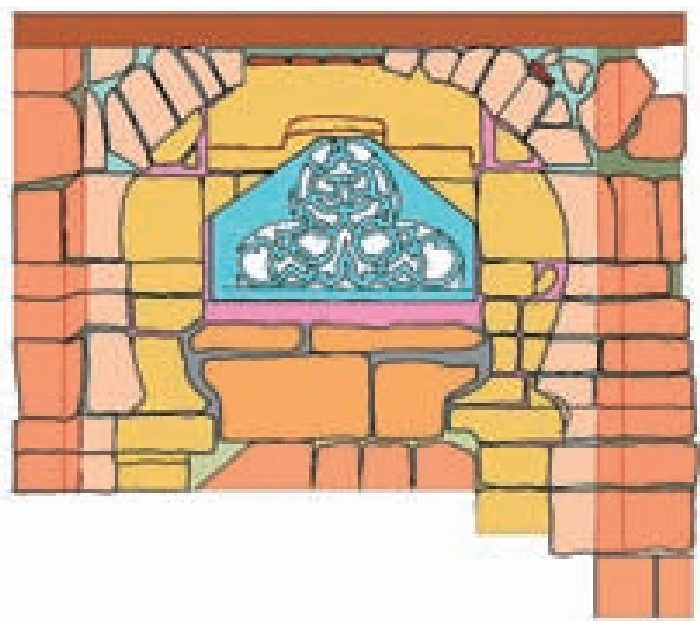

Lámina 20. Cúpula oeste, lado 13

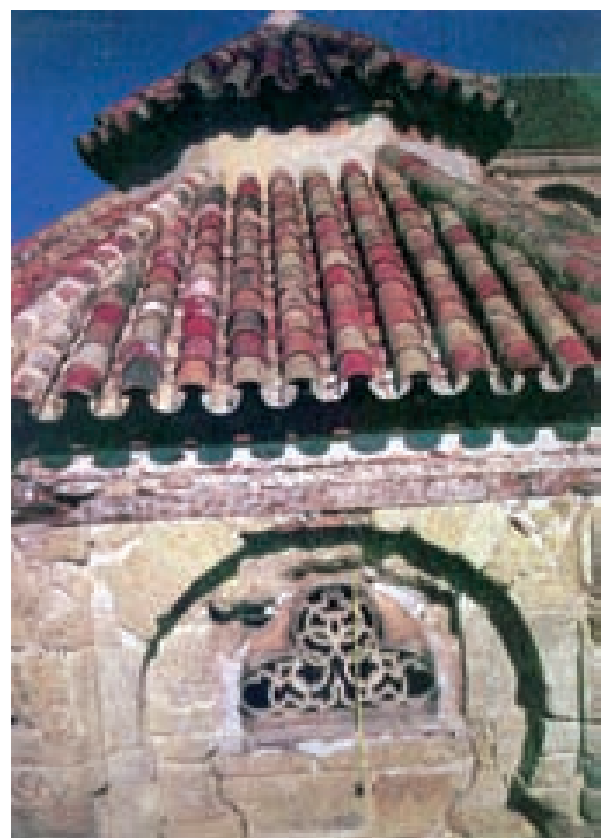

Lámina 21. Cúpula oeste, lado 13 (fotografía del alzado)

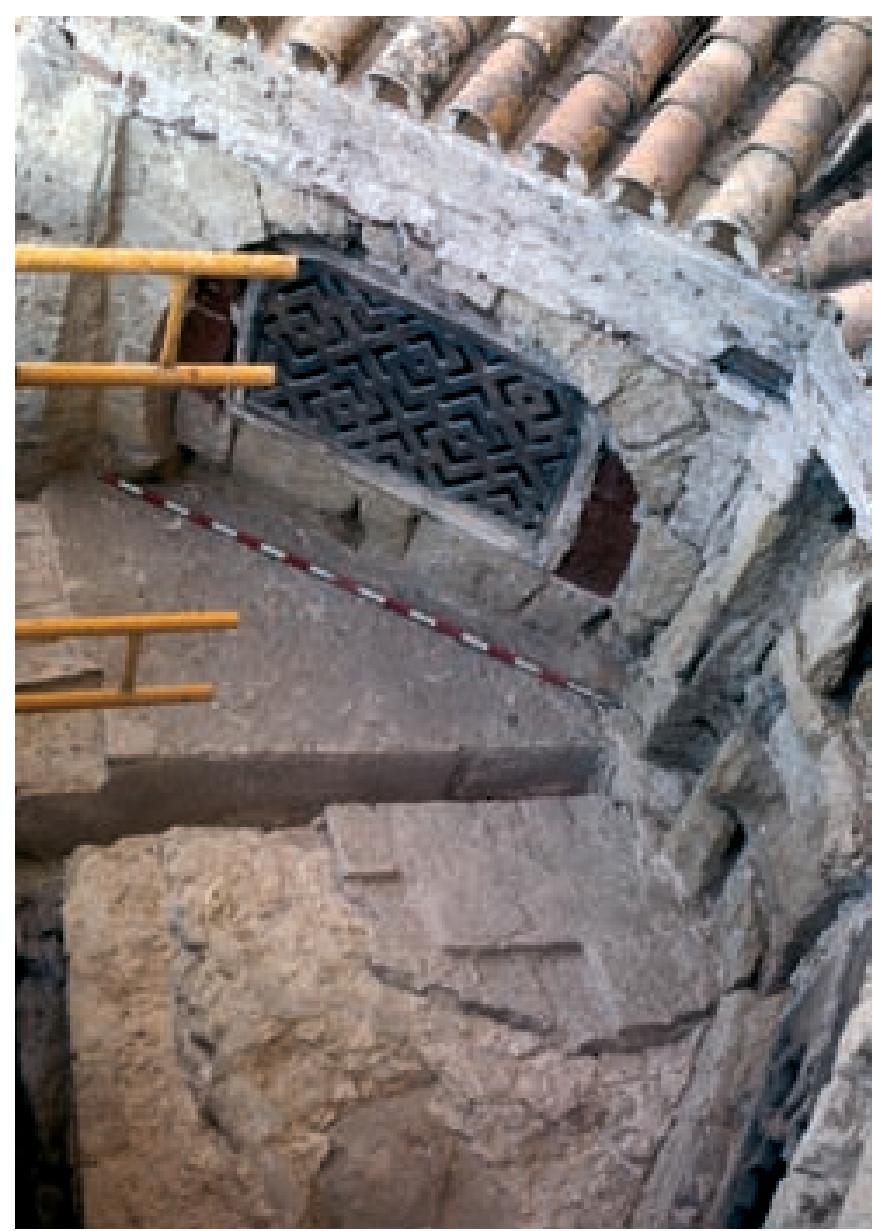

Detalle de la excavación de uno de los rincones existentes en los encuentros de las linternas octogonales, obsérvese la cubierta califal y la canalización existente entre las dos pendientes

Del lado 12 (lámina 19) hemos de poner de relieve la fábrica de ladrillo ejecutada para la colocación de la celosía, siendo el ejemplo más claro para reforzar nuestra idea acerca de las dos fases en las ventanas de estas linternas.

El lado 13 (láminas 20 y 21) es uno de los mejor conservados de esta linterna. Destaca el reflejo del arco lobulado interior en el diseño del exterior. Así como su celosía, labrada ex profeso para el lugar donde se ubica, aunque en la fábrica de la ventana se aprecia el retalle realizado para su encaje en el hueco.

Del lado 14 (lámina 22) destaca la calidad de su celosía, posiblemente labrada ex profeso para ocupar ese lugar, acusando también la presencia de encachado de ladrillos para su colocación.

\section{La excavación de las cubiertas}

La excavación realizada en los rincones que se forman en los encuentros de los muros de las linternas reveló la existencia de restos estructurales de los cupulines. Estos cupulines apa- 


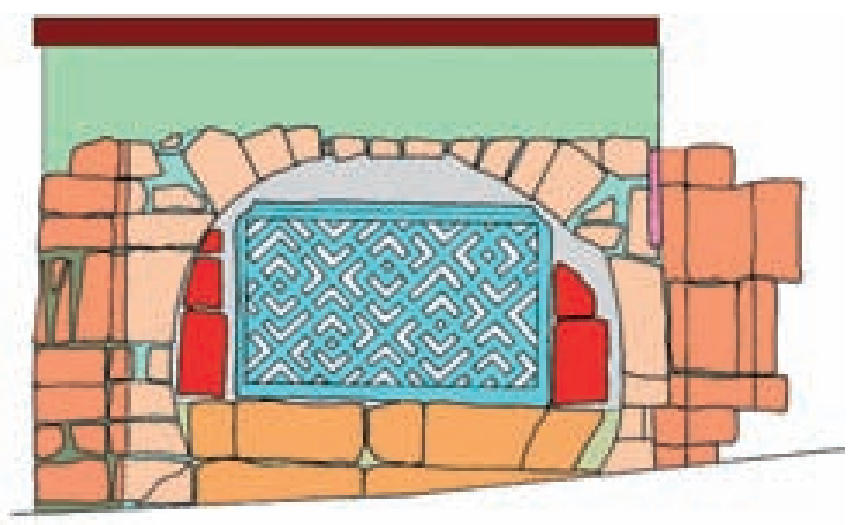

Lámina 22. Cúpula oeste, lado 14

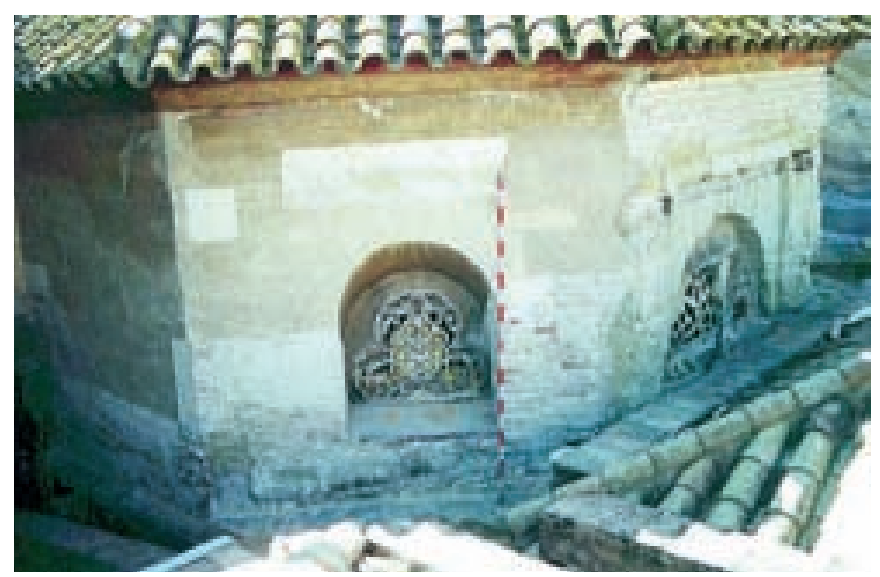

Lámina 23. Cúpula este, zona restaurada en el siglo xvIII

recen como una especie de trompas en el interior de las cúpulas, debajo de cada ventana, no siendo elementos con función constructiva, sino que su aspecto interno es meramente decorativo. La excavación permite afirmar que tapan los huecos resultantes del paso del cuadrado al octógono y que, en sus trasdoses, aparecen piezas de sillería colocadas como cubierta adintelada del espacio resultante. De enorme interés es el hallazgo de niveles originales de cubierta en estos rincones, de lo que se deduce, por ejemplo, que las cubiertas de la mezquita han sido recrecidas más de un metro de altura en fechas históricas no muy lejanas, posiblemente en el siglo XVIII. También podemos saber que dichas cubiertas al menos aquí y en otras zonas constatadas de al-Hakam II, eran de ladrillo colocado de plano y no de tejas curvas. En uno de los rincones y en el encuentro de dos de las pendientes se ha constatado la presencia de una canalización de aguas elaborada con tejas curvas colocadas en posición invertida.

\section{El extradós de la cúpula central}

La investigación arqueológica del extradós de la cúpula central de la Maqsura aporta importantes datos para el conoci-

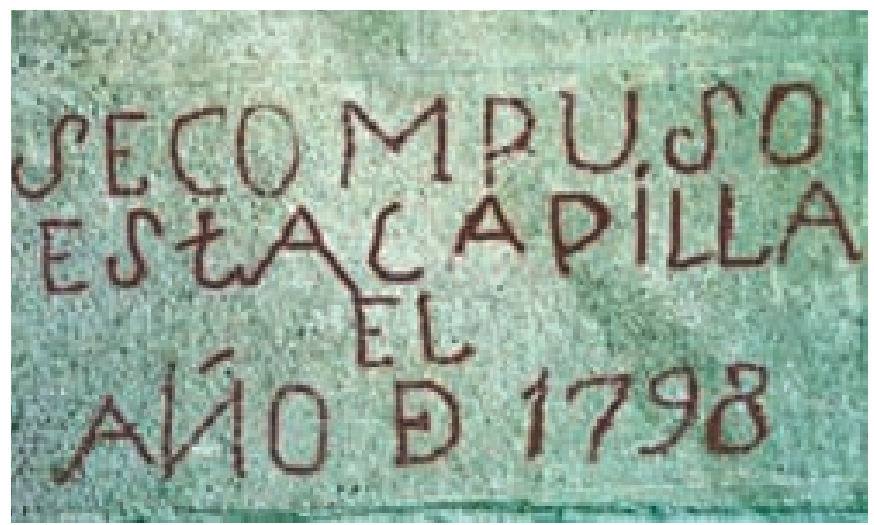

Lámina 24. Grafito en el lado 1 de la linterna este

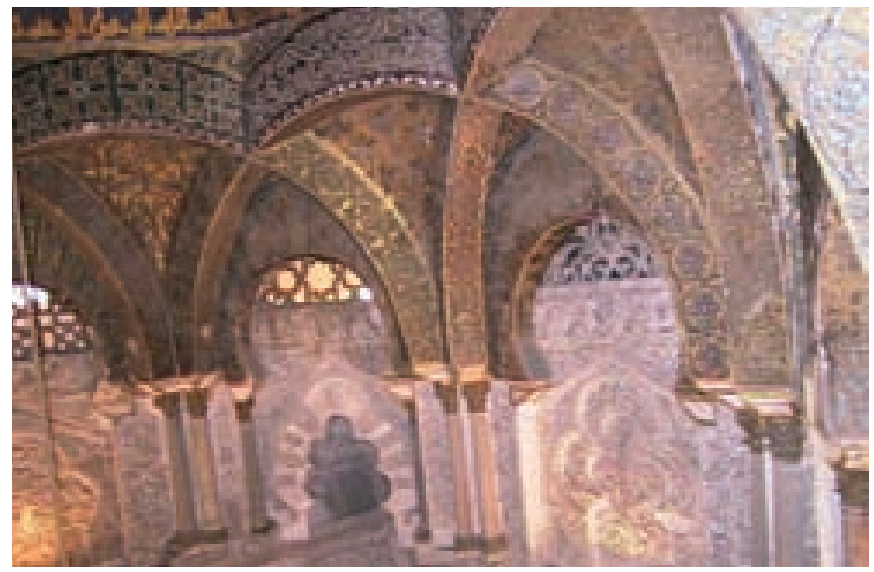

Lámina 25. Arcos entrecruzados que sirven de apoyo al octógono de vigas de madera encadenadas en la cúpula central

miento de aspectos de su técnica constructiva, los cuales ayudan a comprender mejor el significado real de estas cúpulas en la Historia del Arte Hispanomusulmán, así como aportan elementos de juicio para valorar las transformaciones sufridas en su cubierta. El registro de esta zona de la cúpula ha podido realizarse gracias a que la renovación de sus cubiertas ejecutada por Velázquez Bosco en el siglo XIX presenta una estructura de madera que permite visualizar el interior. Cosa que no ocurre en las cúpulas laterales, ya que en estas la cubierta apoya en tabiques de ladrillo que subdividen el espacio interno por lo que no son registrables.

A través del estudio del extradós de la cúpula podemos valorar que ella presenta una fábrica de mampuesto con empleo de abundante argamasa de cal en su elaboración. Destaca la existencia de grandes vigas de madera, entrecruzadas formando un octógono, que servían de atado y apoyo de la cúpula gallonada central. También se conservan los caballetes de ladrillo que servían de apoyo de los pares de la cubierta y las rozas originadas por su colocación en la fábrica de mampuesto de la cúpula. Su estudio revela que en origen se trataba de una cubierta a ocho aguas, de acusa- 


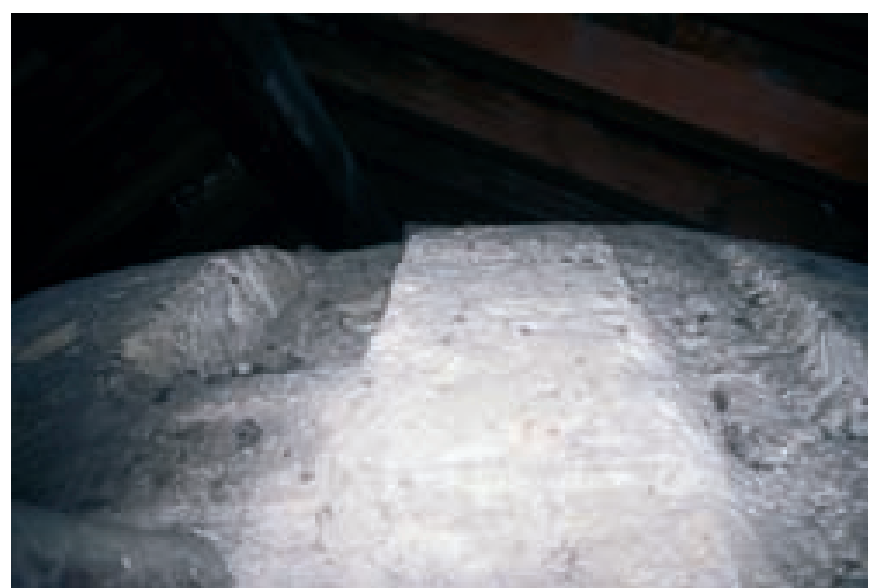

Extradós de la cúpula central. Obsérvese la presencia de rozas de la cubierta islámica

das pendientes y dispuesta muy próxima a la estructura de la cúpula.

Al igual que lo observado en la Capilla de Villaviciosa, se emplean vigas de madera que se cruzan en sus extremos, en este caso 8 vigas. Creándose de esta forma un atado que sirve de apoyo del cuerpo central y que hace la

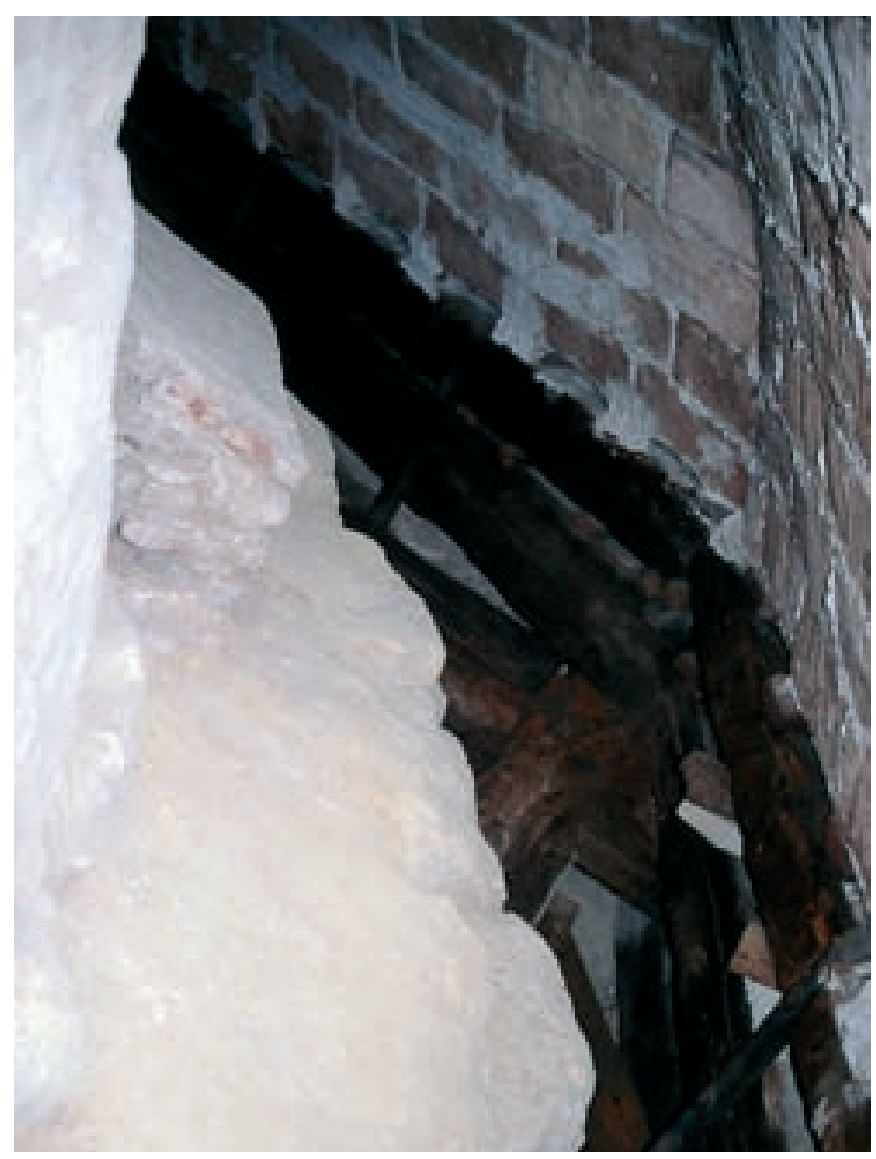

Detalle del extradós de la cúpula central. Obsérvese el apoyo de la cúpula sobre el encadenado de vigas de madera función de elemento de transición entre el cuerpo central y el superior de la cúpula y los arcos entrecruzados que se muestran al interior. Sobre cada uno de dichos arcos se coloca una de estas grandes vigas y, apoyada en ella, se encuentra la estructura de mampuestos de la zona central. Al igual que lo observado en la Capilla de Villaviciosa estos elementos nos hablan de la enorme diferencia existente entre lo que el aspecto interno muestra y la técnica empleada en la construcción.

Las cabezas de las vigas presentan un encaje machihembrado que las encadena, y que queda cobijado dentro de la masa de los pilares angulares de las linternas octogonales.

\section{La cúpula de la capilla de Villaviciosa, un precedente de las cúpulas de la Maqsura}

La cúpula de la Capilla de Villaviciosa se sitúa sobre la antigua ubicación del mihrab de Abd al-Rahmán II. Y a ella se refiere el texto de Ibn al-Nazzam que alude a una gran linterna levantada donde estaba dicho nicho de oración. Su cronología es pocos años anterior a las cúpulas de la maqsura, y puede estimarse, como ha indicado Manuel Nieto, en el 961.

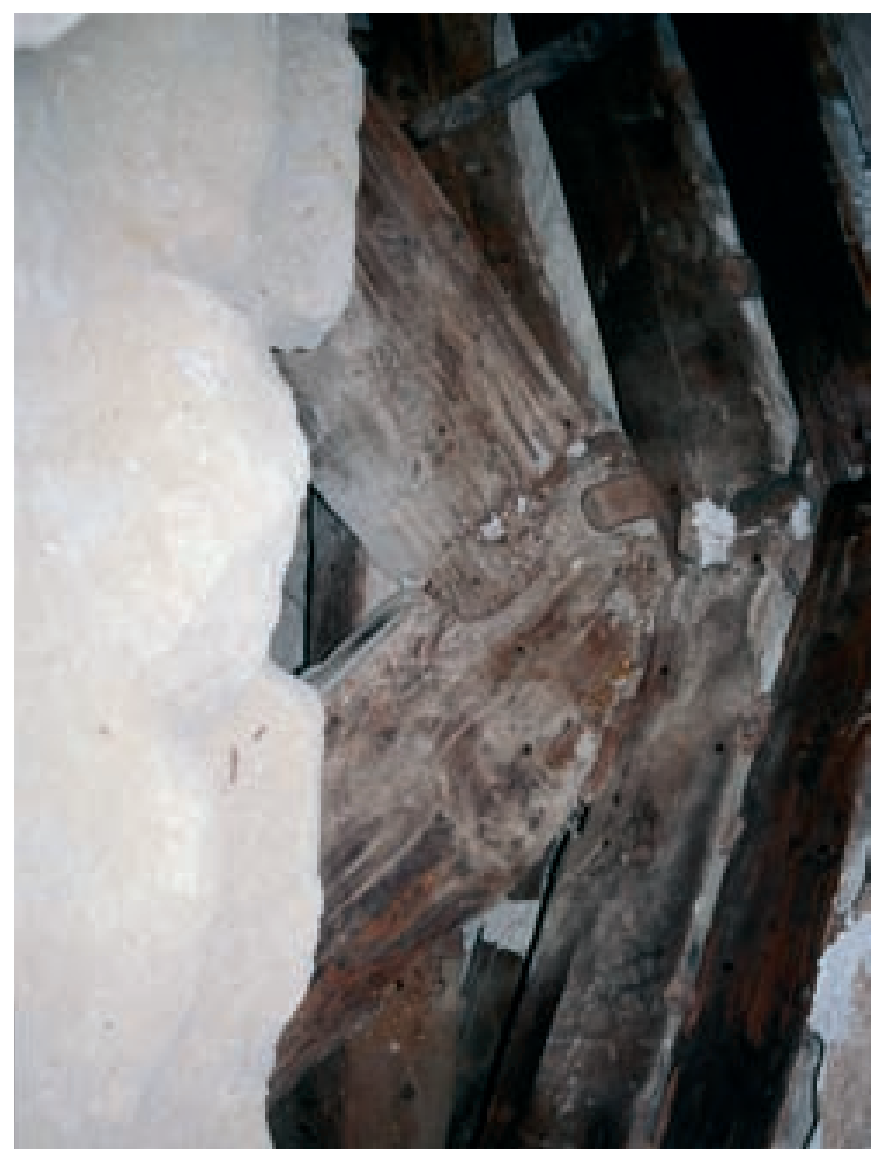

Detalle del encadenado de vigas de madera 
$\mathrm{Al}$ igual que hemos referido con respecto a las cúpulas de la maqsura, en este ejemplar también se observa el primitivismo de su diseño arquitectónico. Y se comprueba a través de su estudio que las valoraciones realizadas acerca de su trascendencia en la evolución de las cúpulas europeas no es tal, y que aparecen por tanto estas piezas cordobesas como un ejercicio o ensayo constructivo cuyas influencias se perderán en el Cristo de la Luz de Toledo.

Es por ello que hemos de dar la razón a la escuela francesa que sopesó en su justa medida esta cuestión. Y podemos recordar la opinión de Terrasse acerca de esta cúpula: Por todas partes se revela en esta cúpula, en la que cabría la tentación de ver una invención arquitectónica, un extraño desconocimiento de problemas arquitectónicos. Esta y las otras cúpulas son obras de decoradores y no de arquitectos... La maravillosa fantasía de las cúpulas cordobesas era a la vez una invención y una renuncia, un éxito y un riesgo.

$\mathrm{Al}$ respecto hemos de poner de relieve la reflexión de Manuel Nieto acerca de la similitud de estas cúpulas con algunos ejemplares armenios de datación más tardía.

La investigación arqueológica del extradós de la cúpula de Villaviciosa ha aportado importantes datos para el conocimiento de aspectos de su técnica constructiva, así como de las transformaciones sufridas en su cubierta. El extradós de la cúpula presenta un gran parecido con el de la cúpula central de la maqsura. En concreto destaca la existencia de marcas dejadas por las vigas que servían de atado y apoyo de su cúpula central, y que en el siglo XV fueron eliminadas al desmontar la cubierta.

Los mechinales en donde apoyaban los pares de la cubierta permanecen respetados en su lado Este, dato que, unido a la presencia de caballetes de ladrillo de apoyo de dichas vigas y de rozas en la fábrica de mampuesto de la cúpula, nos indica que puede estimarse que en origen se trataba de una cubierta a cuatro aguas, de acusadas pendientes y dispuesta próxima a la estructura de la cúpula.

El empleo de vigas que se cruzan para crear un atado con madera que sirva de apoyo del cuerpo central y que sea el elemento de transición entre dicho cuerpo superior de la cúpula y los arcos entrecruzados interiores revela que hay una gran diferencia entre lo que el aspecto interno muestra y la técnica empleada realmente en la construcción. Es más, los cupulines que se levantan al interior de la bóveda en los espacios angulares resultantes del entrecruzamiento de los arcos son meramente decorativos y su misión es decorar esos espacios vacíos de contenido constructivo.

Un aspecto de interés lo presentan los muros que delimitan la linterna al exterior, de planta rectangular y en los que se abren 16 ventanas. Estos muros se levantan sobre una planta de 8,63 por $7,39 \mathrm{~m}$, no produciéndose una

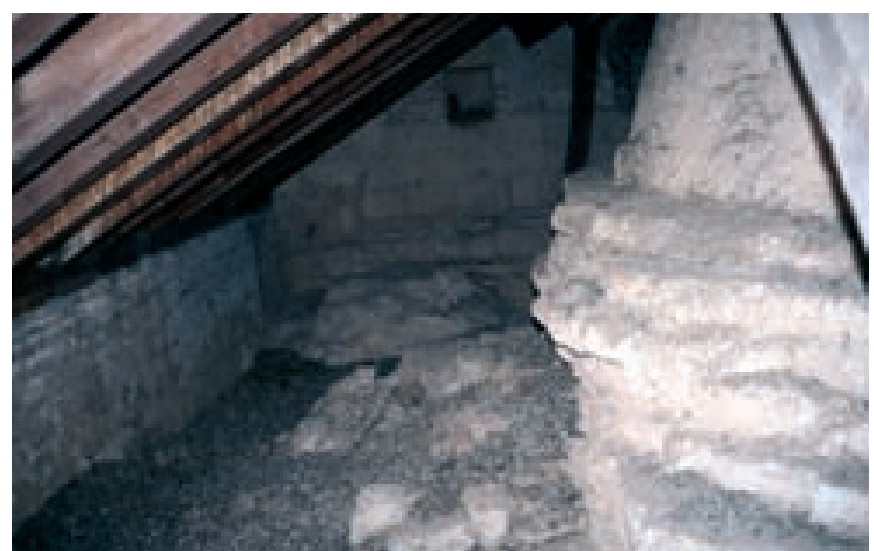

Detalle del extradós de la cúpula de la Capilla de Villaviciosa, estado actual

transición intermedia a la planta octogonal. Esta se logra a través de cruzar cuatro arcos paralelos dos a dos con respecto al rectángulo, uniéndose los puntos medios de los lados adyacentes por medio de otros cuatro arcos que se cruzan

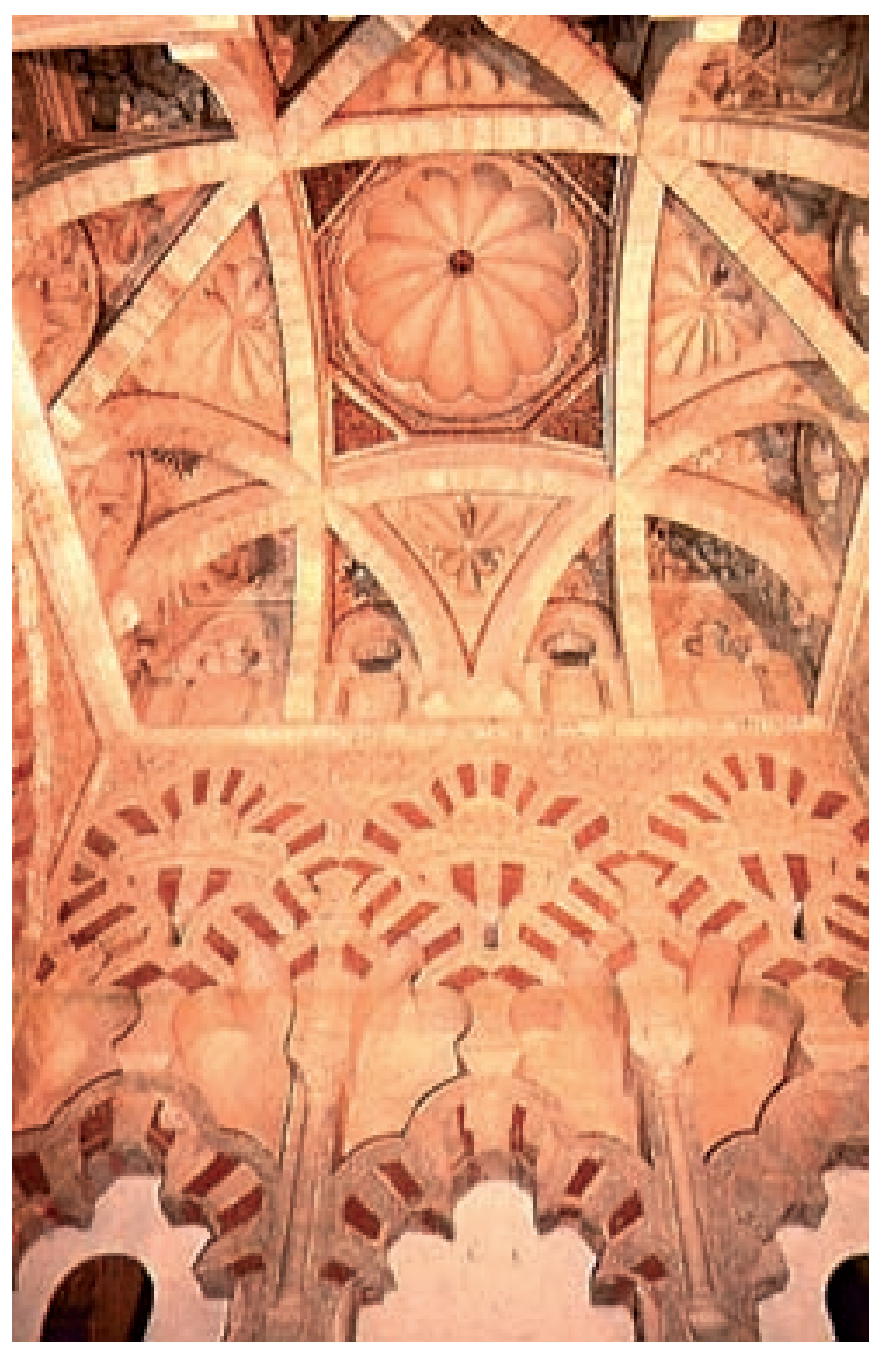

Interior de la cúpula de la Capilla de Villaviciosa 


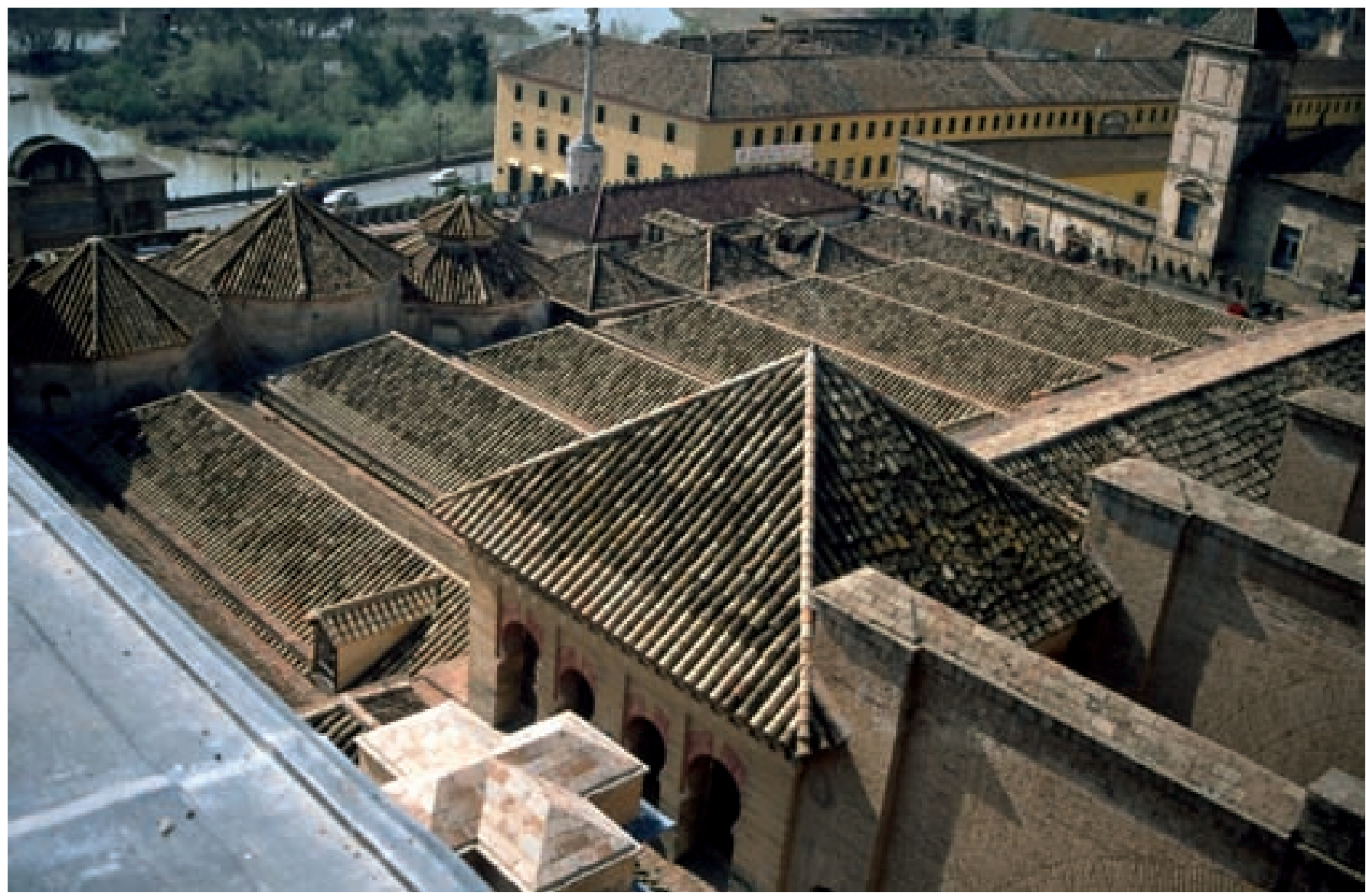

Vista general de las linternas de la Maqsura y su relación con las de la Capilla Real y de la Capilla de Villaviciosa

en las intersecciones de los primeros. Los espacios intermedios se cubren con cupulines decorativos. Estos muros en su zona superior albergaban parte del extradós de la cúpula y servían de apoyo a las vigas de madera que formaban los pares de la cubierta de la linterna. Se conservan los arranques del muro de apoyo de la cubierta, delimitando un espacio en el que se inserta la cúpula.

El estudio de lo conservado de estos muros muestra que, al menos, el lado Este de la cubierta fue desmontado ya en el siglo XIV por la construcción de la capilla Real. Al ser la cúpula de la Capilla Real más alta que la de Villaviciosa, el muro este de la primera se monta sobre el apoyo de la cubierta de la segunda. Es en esta zona superior donde se abren las ventanas de la capilla Real, quedando posteriormente todo este lado amortizado al exterior por la cubierta de la catedral gótica.

Si esta superposición de estructuras en altura es complicada en sí misma y de difícil lectura con relación a los volúmenes exteriores, también reviste complejidad al interior ya que en el hueco de una de las ventanas de la capilla Real, en concreto la primera ventana desde el Norte del lado Oeste, conserva restos de la decoración exterior que coronaba el muro Este de la linterna de al-Hakam II. En concreto se trata de una inscripción trazada sobre el paramento, en cúfico florido, con letras de carácter monumental y que corresponde a la repetición del término al-Mulk («el poder»). No se trata por tanto de una inscripción almohade ni pertenece a una fase primitiva de la decoración del interior de la capilla Real, sino que son los escasos restos conservados de lo que debió ser el friso que coronaba al exterior la linterna califal. Por tanto, y en relación con este último dato, creemos que las transformaciones sufridas por la linterna y la cubierta de la cúpula de Villaviciosa son las causantes de la confusión sobre el origen islámico de la capilla Real.

Se conserva in situ una celosía islámica de esta linterna, la de la ventana situada más al Oeste de su lado Norte. $\mathrm{Su}$ situación escondida y de difícil acceso ha facilitado su conservación frente a la pérdida del resto de celosías de estas 16 ventanas. Se trata de una pieza marmórea que presenta un desarrollo de arcos lobulados entrecruzados, que imitan a las arquerías del interior del templo; su esmerada factura llega hasta el detalle de tener labrados pequeños capiteles y fustes. 


\section{Bibliografía}

Aguilar Priego, R., 1945, Datos inéditos sobre la restauración del Mihrab de la Mezquita de Córdoba, BRAC, 55, pp. 139-66.

AL-IDRISI, 1949 (fuente del 1154), Walf al-Masjid al-Jami bi-Qurtuba, texto y trad. de A. Dessus Lamare, Alger.

BECKWITH, J., 1960, Caskets from Cordova, Londres.

BRISCH, K., 1961, Las celosías de las fachadas de la Gran Mezquita de Córdoba, Al-Andalus, XXVI, pp. 398-426.

Chueca Goitia, F., 1968, La Mezquita de Córdoba, Granada.

EWERT, C., 1968, Spanisch-islamische Systeme sich kreuzender Biigen. l. Die senkrechten ebenen Systeme sich kreuzender Biigen als Stützkonstruktionen der vier Rippen-kuppeln in der ehemaligen Hauptmoschee von Córdoba, Berlín.

MARÇAIS, G., 1965, Sur les mosaiques de la Grande Mosquée de Cordoue, en Studies in Honour of Professor K. A. C. Creswell, El Cairo, pp. 147-56.

MARFIL, P., 1998, Trabajos de investigación arqueológica en las cúpulas de la Maqsura de la Mezquita de Córdoba, Qurtuba 3, pp. 250-252.

MARFIL, P., 1998, Nuevos datos para el conocimiento del lucernario de al-Hakam II en la Capilla de Villaviciosa de la Mezquita de Córdoba, Qurtuba 3, pp. 252-253.

MarfiL, P., 2001, La Mezquita de Córdoba, en El Esplendor de los Omeyas Cordobeses, Granada, pp. 45-48.
Nieto Cumplido, M., 1998 La Catedral de Córdoba, Córdoba.

OCAÑA, M., 1988-90, Inscripciones árabes fundacionales de la Mezquita-Catedral de Córdoba, Cuadernos de Madinat Al-Zahra 2, pp. 9-28.

OCAÑA, M., 1996, Las inscripciones del mihrab de la Gran Mezquita de Córdoba y la incógnita de su data, en H. STERN, LES MOSAIQUES, Berlín, 1976, pp. 48-52. Reimpresión en Qurtuba 1, pp. 287-293.

Ortiz JuÁreZ, D., 1982, La cúpula de la Capilla Real de la Catedral de Córdoba, posible obra almohade, Boletín de La Asociación Española de Orientalistas XVIII, pp. 197-215.

Ortiz JuÁreZ, D., 1983, La cúpula islámica de la Capilla Real de la Catedral de Córdoba, en III Jornadas de Cultura Árabe e Islámica, Madrid.

Romero de Torres, E., 1935, Aportaciones para la Historia de la Catedral de Córdoba: la famosa capilla del Mihrab, que amenazaba hundirse en la segunda mitad del siglo XVIII, fue restaurada por el arquitecto francés D. Baltasar Dreveton, BRAC 48, pp. 83-86.

TORRES BALBÁs, L., 1936, Reparación en la techumbre de la Mezquita de Córdoba en el siglo XIII, Al-Andalus IV, pp. 171-173.

TORRES BALBÁS, L., 1936-9, Restauración, en el siglo XVIII, de la cúpula que precede al mihrab de la Mezquita de Córdoba, Al-Andalus IV, pp. 198-200.

TORRES BALbÁs, L., 1940, Las cúpulas de las más importantes mezquitas españolas y tunecinas en los siglos IX y X, Al-Andalus V, pp. 391-396. 